\title{
Binge-eating disorder diagnosis and treatment: a recap in front of DSM-5
}

\author{
Federico Amianto ${ }^{2}$ Luisa Ottone, Giovanni Abbate Daga and Secondo Fassino
}

\begin{abstract}
Introduction: Binge Eating Disorders is a clinical syndrome recently coded as an autonomous diagnosis in DSM-5. Individuals affected by Binge Eating Disorder (BED) show significantly lower quality of life and perceived health and higher psychological distress compared to the non-BED obese population. BED treatment is complex due to clinical and psychological reasons but also to high drop-out and poor stability of achieved goals. The purpose of this review is to explore the available data on this topic, outlining the state-of-the-art on both diagnostic issues and most effective treatment strategies.

Methods: We identified studies published in the last 6 years searching the MeSH Term "binge eating disorder", with specific regard to classification, diagnosis and treatment, in major computerized literature databases including: Medline, PubMed, PsychINFO and Science Direct.

Results: A total of 233 studies were found and, among them, 71 were selected and included in the review.

Review: Although Binge Eating Disorder diagnostic criteria showed empirical consistency, core psychopathology traits should be taken into account to address treatment strategies. The available body of evidence shows psychological treatments as first line interventions, even if their efficacy on weight loss needs further exploration. Behavioral and self-help interventions evidenced some efficacy in patients with lower psychopathological features. Pharmacological treatment plays an important role, but data are still limited by small samples and short follow-up times. The role of bariatric surgery, a recommended treatment for obesity that is often required also by patients with Binge Eating Disorder, deserves more specific studies. Combining different interventions at the same time does not add significant advantages, planning sequential treatments, with more specific interventions for non-responders, seems to be a more promising strategy.

Conclusions: Despite its recent inclusion in DSM-5 as an autonomous disease, BED diagnosis and treatment strategies deserve further deepening. A multidisciplinary and stepped-care treatment appears as a promising management strategy. Longer and more structured follow-up studies are required, in order to enlighten long term outcomes and to overcome the high dropout rates affecting current studies.
\end{abstract}

Keywords: Binge eating disorder, Overeating, Obesity, Eating disorders, Treatment

\section{Introduction}

The fifth edition of Diagnostic and Statistical Manual of Mental Disorders (DSM-5) [1] published in May 2013, codes for the first time Binge Eating Disorder (BED) as an autonomous Eating Disorder (ED), while before it was listed as an Eating Disorder not Otherwise Specified (EDNOS) needing future definition. This disease is of particular interest for its frequency in primary care, its

\footnotetext{
* Correspondence: federico.amianto@unito.it

* Correspondence: federico.amianto@unito.it Cherasco 11, 10126 Turin, Italy
}

link with obesity and its medical and psychiatric comorbidities, leading to high socio-economic impact due to reduced quality of life and increased health service utilization [2,3]. It is in fact a relatively common disorder, with an estimated lifetime prevalence in general population around 1.4\% [4]. However, this estimate substantially increases among obese individuals with no marked gender differences [4]. Prevalence is likely to increase, especially because of the rising incidence that both obesity and EDs show worldwide rather than for the widening of diagnostic criteria introduced in DSM-5 $[5,6]$.

\section{Biomed Central}

(C) 2015 Amianto et al.; licensee BioMed Central. This is an Open Access article distributed under the terms of the Creative Commons Attribution License (http://creativecommons.org/licenses/by/4.0), which permits unrestricted use, distribution, and reproduction in any medium, provided the original work is properly credited. The Creative Commons Public Domain Dedication waiver (http://creativecommons.org/publicdomain/zero/1.0/) applies to the data made available in this article, unless otherwise stated. 
Though BED was initially considered a disorder of adulthood, recent studies furthermore suggest a lower age of onset than that previously assumed [4]. Increasing evidence is emerging that it already occurs in adolescence and childhood, with an average age of onset ranging from late teens to early 20 s and a mean persistence of 4.3 years [4]. An earlier onset of bingeing seems to predict worse outcome and to require more complex interventions [7]. In addition, although there is still a wide debate on the clinical stability of such a diagnosis, data showed that it tends to be a stable syndrome, with relative stability of binge eating patterns [8] and lower crossover rates than other EDs [9].

The clinical importance of BED is also related to its frequent comorbidity with obesity as well as complications of overweight [4] and with psychiatric symptoms like depression and anxiety, frequently linked to excessive concerns about food, body shape and weight $[10,11]$. Moreover, like other EDs, BED patients show relevant alexithymia and deficit in emotional identification and regulation [12,13] and high interpersonal problems $[14,15]$. Personality disorders are also frequently diagnosed among BED patients and mood disorders and substance abuse are frequent comorbidities $[4,16]$, eventually related to more severe psychopathology and worse prognosis [17-19]. These correlations are so relevant that these comorbidities have been proposed as markers of major severity, rather than just associated conditions [19].

Also due to these relevant comorbidities, perceived quality of life and health are significantly lower in BED than in the non-BED obese population, with great expression of depressive and negative feelings, disinhibition and anger $[11,13,20]$. Low mood and negative feelings seem to be related to severe eating impulsiveness, leading to significant psychopathological impairment even in presence of a limited food assumption [13,18]. Eating impulsiveness itself has been related to greater physical discomfort and worse quality of life, independently from Body Mass Index (BMI) and objective functional impairment, and it is also consequently related to higher treatment seeking [15,20,21].

The clinical relevance of BED, here underlined, highlights the importance of identifying appropriate and evidence based treatment strategies, in order to prevent this disorder to become chronic and complicated [4]. It is the purpose of this review to explore the state-of-theart on this topic, exposing current evidence on diagnosis and treatment.

\section{Methods}

We aimed to systematically identify and synthesize the recent evidences about BED diagnostic category with regards to its recent addition as an autonomous disease in DSM-5, with a focus on its clinical features, psychopathological correlates and treatment evidences. In relation to these issues, we summarized the principal findings published from January 2008 to May 2014 about this topic. We choose this time frame because the first articles claiming BED inclusion in DSM-5 in online databases date back this year [22]. We identified relevant studies searching the MeSH Term "binge eating disorder", with specific regard to classification, diagnosis and treatment, in major computerized literature databases including: Medline, PubMed, PsychINFO and Science Direct. We focused on clinical studies about adult population, excluding studies about children and young adults. We also excluded from the evaluation case reports and case series studies.

Any experimental research that is reported in the manuscript has been performed with the approval of an appropriate ethics committee. Research carried out on humans are in compliance with the Helsinki Declaration, and experimental research on animals follows internationally recognized guidelines.

\section{Results}

A total of 233 studies were found and 71 were included in this review according to the aforementioned criteria (see Table 1 for a summary). To enhance the specificity of our search, we considered only studies based on the specific diagnosis of BED. We therefore excluded 64 studies pertaining to mixed ED samples, non-purging bulimia nervosa, atypical EDs, EDNOS, if not including $\mathrm{BED}$, physical comorbidities of binge eating and obesity or the ICD-10 category "overeating associated with other psychiatric condition”. We also excluded 24 studies referring to sub-threshold BED, a clinical category meant to be redefined by the application of diagnostic criteria for EDs in DSM-5.

Because of their limited usefulness in clinical practice, they were excluded 30 studies referring to neurobiological, neurocognitive and endocrine correlates of BED, 12 studies referring to laboratory tests and drugs not available in commerce, and 10 studies about diagnostic test validity. Twelve more excluded studies concerned secondary descriptive characteristics of BED, and 5 were about binge eating specificities among ethnic minorities. Five studies were not accessible to reading because written in languages different from English or Italian.

\section{Review}

Diagnostic issues and pathological features

According to the biopsychosocial model of mental diseases a comprehensive assessment and understanding of psychopathological mechanisms, maintenance factors, and dysfunctional areas of psychiatric illnesses are useful to support and address therapeutic interventions [23]. 
Table 1 Summary of studies included in the review*

\begin{tabular}{|c|c|c|c|c|c|c|c|}
\hline Thematic area & Article $\mathrm{n}$. & Authors & Patients $n . /$ Articles $n$. & $\begin{array}{l}\text { Duration } \\
\text { (months) }\end{array}$ & Drop-out rates & Main results & Type of study \\
\hline \multirow[t]{8}{*}{$\begin{array}{l}\text { Diagnostic issues and } \\
\text { pathological features }\end{array}$} & 23 & $\begin{array}{l}\text { Bautista-Diaz et al., } \\
2012 \text { [21] }\end{array}$ & $\begin{array}{l}70 \text { obese women } \\
\text { (35 BED; } 35 \text { non BED) }\end{array}$ & -—— & -—— & $\begin{array}{l}\text { Higher body dissatisfaction and stronger } \\
\text { influence of socio-cultural factors on } \\
\text { eating psychopathology (at self-administered } \\
\text { test) in women with BED vs controls. }\end{array}$ & Case-control study \\
\hline & & $\begin{array}{l}\text { Blomquist et al., } \\
2011 \text { [49] }\end{array}$ & 78 obese with BED & -—— & -—- & $\begin{array}{l}\text { Mean weight gain of } 15.1 \text { pounds during } \\
\text { the year before treatment in BED patients } \\
\text { (structured interviews + self-administered } \\
\text { test). Weight change associated with more } \\
\text { frequent binge eating and overeating } \\
\text { during breakfasts. }\end{array}$ & $\begin{array}{l}\text { Retrospective } \\
\text { observational study }\end{array}$ \\
\hline & & $\begin{array}{l}\text { Blomquist et al., } \\
2012 \text { [14] }\end{array}$ & 84 obese with BED & -—— & -—- & $\begin{array}{l}\text { Higher interpersonal problems (at interpersonal } \\
\text { circumplex structural summary method) } \\
\text { observed in in BED patients and associated } \\
\text { with earlier onset of binges and overweight. }\end{array}$ & Cross-sectional study \\
\hline & & $\begin{array}{l}\text { Carano et al., } \\
2012[12]\end{array}$ & 80 BED & -—— & -—— & $\begin{array}{l}\text { Among BED patients, } 27.5 \% \text { refer suicide } \\
\text { ideation and } 12.5 \% \text { previous attempts of } \\
\text { suicide (self-administered tests). Alexithymia } \\
\text { related to higher suicide ideation and } \\
\text { previous suicide attempts. }\end{array}$ & Cross-sectional study \\
\hline & & $\begin{array}{l}\text { Carrard et al., } \\
2012[18]\end{array}$ & $\begin{array}{l}92 \text { women with BED } \\
\text { (full-criteria and } \\
\text { subthreshold) }\end{array}$ & 6 treatment & $10.6-30.8 \%$ & $\begin{array}{l}\text { Participants to an internet self-help program } \\
\text { split by cluster analyses into pure dietary } \\
\text { subtype ( } 71.7 \%) \text { and dietary-negative affect } \\
\text { subtype (28.3\%) (clinical interview + } \\
\text { self-administered tests). Dietary-negative } \\
\text { affect subtype show higher frequency of } \\
\text { binges, more severe eating disorders, higher } \\
\text { tendency to act rashly in the context of } \\
\text { negative affect, greater sensitivity to } \\
\text { punishment and higher dropout rates } \\
(30.8 \% \text { vs } 10.6 \%) \text {. }\end{array}$ & Case-control study \\
\hline & & $\begin{array}{l}\text { Compare et al., } \\
2012 \text { [13] }\end{array}$ & $\begin{array}{l}150 \text { obese BED; } \\
150 \text { obese non BED; } \\
150 \text { healthy controls }\end{array}$ & -二- & & $\begin{array}{l}\text { Lower mindfulness scores (Five Facet } \\
\text { Mindfulness Questionnaire) in BED patients } \\
\text { than in healthy and obese controls. } \\
\text { Mindfulness negatively correlated with } \\
\text { binge frequency, body uneasiness and } \\
\text { eating impulsivity (self-administered tests). }\end{array}$ & Case-control study \\
\hline & & $\begin{array}{l}\text { Folope et al., } \\
2012 \text { [20] }\end{array}$ & 130 obese & -—- & & $\begin{array}{l}\text { Presence of EDs impaired significantly } \\
\text { quality of life and is related to higher } \\
\text { anxiety and depression rates } \\
\text { (self-administered tests). }\end{array}$ & Cross-sectional study \\
\hline & & $\begin{array}{l}\text { Gianini et al., } \\
2013 \text { [30] }\end{array}$ & 326 obese with BED & -—- & -—- & $\begin{array}{l}\text { Difficulties with emotion regulation } \\
\text { accounted for unique variance in both } \\
\text { emotional overeating and general eating } \\
\text { pathology (self-administered tests). }\end{array}$ & Cross-sectional study \\
\hline
\end{tabular}


Table 1 Summary of studies included in the review* (Continued)

\begin{tabular}{|c|c|c|c|c|c|}
\hline $\begin{array}{l}\text { Grilo et al., } \\
2009 \text { [27] }\end{array}$ & $\begin{array}{l}436 \text { (195 BED with } \\
\text { overvaluation; } 129 \\
\text { BED subclinical } \\
\text { overvaluation; } 61 \text { BN; } \\
51 \text { sub-threshold BN) }\end{array}$ & -—- & -- & $\begin{array}{l}\text { Clinical overvaluation of body shape and } \\
\text { weight present in } 60 \% \text { of BED and related } \\
\text { to significantly higher levels of eating } \\
\text { disorder psychopathology. BED clinical } \\
\text { overvaluation group show higher eating } \\
\text { concern, shape concern, and weight } \\
\text { concern than other groups. This feature } \\
\text { warrants consideration either as a diagnostic } \\
\text { specifier or as a dimensional severity rating. }\end{array}$ & Case-control study \\
\hline $\begin{array}{l}\text { Grilo et al., } \\
2013^{1}[10]\end{array}$ & $\begin{array}{l}90 \text { BED (52 with } \\
\text { overvaluation; } 38 \\
\text { without overvaluation) }\end{array}$ & $\begin{array}{l}6 \text { treatment }+12 \\
\text { follow-up }\end{array}$ & $\begin{array}{l}24 \%(C B T)-31 \% \\
(B W L)\end{array}$ & $\begin{array}{l}\text { Participants randomly assigned to group } \\
\text { CBT or BWL. Patients with overvaluation of } \\
\text { weight and body shape had significantly } \\
\text { greater levels of ED psychopathology, } \\
\text { higher depression and lower self-esteem } \\
\text { (semi-structured interviews + clinical } \\
\text { measures). Overvaluation of shape/weight } \\
\text { predicts non-remission from BED and higher } \\
\text { frequency of binge eating at } 12 \text {-month } \\
\text { follow-up. }\end{array}$ & Prospective study \\
\hline $\begin{array}{l}\text { Hudson et al., } \\
2012[5]\end{array}$ & $\begin{array}{l}888 \text { first-degree } \\
\text { relatives from a } \\
\text { family study of BED }\end{array}$ & -—- & -—- & $\begin{array}{l}\text { Using the proposed DSM-5 diagnostic } \\
\text { criteria vs DSM-IV criteria (clinical interview) } \\
\text { will likely have only a minimal effect on } \\
\text { global BED prevalence. }\end{array}$ & Prevalence study \\
\hline $\begin{array}{l}\text { Masheb et al., } \\
\text { 2011a [32] }\end{array}$ & $\begin{array}{l}311 \text { women (39 BN; } \\
69 \text { BED; } 203 \text { controls) }\end{array}$ & -二- & -—— & $\begin{array}{l}\text { Atypical eating patterns (e.g. nibbling, } \\
\text { eating double meals and nocturnal eating) } \\
\text { more frequent among EDs (at internet } \\
\text { questionnaire). Breakfast consumption } \\
\text { associated with lower BMI in BED and } \\
\text { controls and more frequent meal } \\
\text { consumption associated with less binge } \\
\text { eating in BED. }\end{array}$ & Case-control study \\
\hline $\begin{array}{l}\text { Masheb et al., } \\
2013 \text { [50] }\end{array}$ & 130 obese with BED & -— & - - & $\begin{array}{l}83 \% \text { of treatment seeking obese BED } \\
\text { patients gained weight in year before } \\
\text { treatment (structured interview + self-report } \\
\text { questionnaires). No differences among } \\
\text { weight gainers and weight maintainers/losers } \\
\text { in current weight and eating behaviors. }\end{array}$ & $\begin{array}{l}\text { Retrospective } \\
\text { observational study }\end{array}$ \\
\hline $\begin{array}{l}\text { Munsch et al., } \\
\text { 2012a [31] }\end{array}$ & 22 women with BED & - & - & $\begin{array}{l}\text { During binge days (at } 1 \text { week of ecological } \\
\text { assessment) negative mood and tension } \\
\text { are higher and significantly increased at } \\
\text { first binge episode, while positive mood } \\
\text { strongly and significantly decreased. No } \\
\text { indications of accumulation of negative } \\
\text { mood triggering binges followed by } \\
\text { reinforcing mechanisms in terms of } \\
\text { improvement of mood, unlikely to BN. }\end{array}$ & Cross-sectional study \\
\hline
\end{tabular}

measures) Overvaluation of shape/weight

predicts non-remission from BED and higher

follow-up criteria vs DSM-IV criteria (clinical interview) global BED prevalence.

Atypical eating patterns (eg. nibbling. mo double meals and nocturnal eating) associated with lower BMI in BED and controls and more frequent meal eating in BED.

$83 \%$ of treatment questionnaires). No differences among . ent weight and eating behaviors. mprovement of mood, unlikely to BN. 
Table 1 Summary of studies included in the review* (Continued)

\begin{tabular}{|c|c|c|c|c|c|}
\hline $\begin{array}{l}\text { Ojserkis et al., } \\
2012[28]\end{array}$ & $\begin{array}{l}116 \text { BED ( } 84 \text { with } \\
\text { overvaluation, } 31 \\
\text { without overvaluation; } \\
1 \text { excluded) }\end{array}$ & 4 treatment & $52.25 \%$ & $\begin{array}{l}\text { Patients selected from a 16-week randomized } \\
\text { controlled trial of BWL + individual CBT and/or } \\
\text { fluoxetine**. Patients with overvaluation of } \\
\text { weight and body shape show higher } \\
\text { pre-treatment scores on depression and } \\
\text { eating psychopathology and lower } \\
\text { self-esteem (self-administered tests). At } \\
\text { treatment termination patients with } \\
\text { overvaluation still display high binge } \\
\text { eating severity. }\end{array}$ & $\begin{array}{l}\text { Prospective } \\
\text { observational study }\end{array}$ \\
\hline $\begin{array}{l}\text { Peterson et al., } \\
2012[8]\end{array}$ & $\begin{array}{l}188 \mathrm{EDs}(71 \mathrm{AN}, 95 \mathrm{BN}, \\
122 \mathrm{BED})\end{array}$ & 2 follow-up & $0 \%$ & $\begin{array}{l}\text { Although longitudinal patterns of binge } \\
\text { types are variable among individuals with } \\
\text { EDs, consistency in objective and subjective } \\
\text { binge episodes is most commonly observed. }\end{array}$ & $\begin{array}{l}\text { Retrospective } \\
\text { observational study }\end{array}$ \\
\hline $\begin{array}{l}\text { Sawaoka et al., } \\
2012 \text { [15] }\end{array}$ & $\begin{array}{l}113 \text { overweight or } \\
\text { obese with BED }\end{array}$ & -—- & -—- & $\begin{array}{l}\text { Social anxiety positively and significantly } \\
\text { related with shape and weight concerns } \\
\text { and binge frequency (semi structural } \\
\text { clinical interviews + self-report measure). } \\
\text { Social anxiety and self-consciousness } \\
\text { account for significant variance in eating, } \\
\text { shape and weight concerns and ED severity } \\
\text { but are not associated with BMI or dietary } \\
\text { restraint. }\end{array}$ & Cross-sectional study \\
\hline $\begin{array}{l}\text { Schag et al., } \\
2013 \text { [16] }\end{array}$ & 51 articles & -—- & -—- & $\begin{array}{l}\text { Evidences of increased food-related impulsivity, } \\
\text { coupled with increased reward sensitivity, in } \\
B E D \text { patients. BED could represent a specific } \\
\text { phenotype of obesity with increased } \\
\text { food-related impulsivity. }\end{array}$ & Literature review \\
\hline $\begin{array}{l}\text { Striegel-Moore \& } \\
\text { Franko, } 2008 \text { [22] }\end{array}$ & - - & 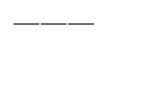 & --_- & $\begin{array}{l}\text { Clinical utility and validity of BED diagnostic } \\
\text { criteria is consistent and allow BED inclusion } \\
\text { in DSM-V. }\end{array}$ & Literature review \\
\hline $\begin{array}{l}\text { Thomas et al., } \\
2009 \text { [25] }\end{array}$ & 125 articles & -—- & -—- & $\begin{array}{l}\text { EDNOS did not differ significantly from AN } \\
\text { and BED on eating or general psychopathology } \\
\text { while BN show greater eating and general } \\
\text { psychopathology. Subthreshold BN or BED } \\
\text { did not differ significantly from full syndrome } \\
\text { cases. }\end{array}$ & Meta-analysis \\
\hline $\begin{array}{l}\text { Trace et al., } \\
2012 \text { [6] }\end{array}$ & 13295 female twins & - - & -—- & $\begin{array}{l}\text { Lifetime prevalence of BN and BED increased } \\
\text { linearly as the frequency criterion for binges } \\
\text { decreased. As required duration increased, } \\
\text { BED prevalence decreased slightly. }\end{array}$ & Prevalence study \\
\hline $\begin{array}{l}\text { White \& Grilo, } \\
2011 \text { [26] }\end{array}$ & $\begin{array}{l}916 \text { community } \\
\text { volunteers (164 BED, } \\
83 \text { BN, } 668 \text { healthy } \\
\text { controls) }\end{array}$ & -—— & -—— & $\begin{array}{l}\text { All of the BED diagnostic criteria in DSM.IV } \\
\text { have predictive value. Eating alone because } \\
\text { embarrassed and feeling disgusted performed } \\
\text { as the best inclusion and exclusion criteria, } \\
\text { respectively. Eating when not hungry and } \\
\text { eating alone because embarrassed are the } \\
\text { best overall indicators for binge eating. }\end{array}$ & Cross sectional study \\
\hline
\end{tabular}

Social anxiety positively and significantly Cross-sectional study ed with shape and weight concerns clinical interviews + self-report measure). Social anxiety and self-consciousness ccount for significant variance in eating, she and weight concerns and ED severity straint. coupled with increased reward sensitivity, in Datients. BED could represent a specific food-related impulsivity.

Clinical utility and validity of BED diagnostic in DSM-V. D on eating or general psychopathology while $B N$ show greater eating and general did not differ significantly from full syndrom cases. nearly as the frequency criterion for binges

All of the BED diagnostic criteria in DSMIV have predictive value. Eating alone because as the best inclusion and exclusion criteria eating alone because embarrassed are the best overall indicators for binge eating. 
Table 1 Summary of studies included in the review* (Continued)

\begin{tabular}{|c|c|c|c|c|c|c|c|}
\hline & & $\begin{array}{l}\text { Wolfe et al.. } \\
2009 \text { [33] }\end{array}$ & 33 articles & -—— & -一- & $\begin{array}{l}\text { Majority of binge episodes typically occur in } \\
\text { less than } 2 \text { h, with size variability across BN } \\
\text { and BED but a clinical importance likely } \\
\text { related to objective food intake and an } \\
\text { increased consumption of carbohydrates } \\
\text { and fats. Loss of control is a core feature } \\
\text { associated with higher depression, higher } \\
\text { body dissatisfaction and poorer related } \\
\text { quality of life. Negative affect is the most } \\
\text { widely reported binge antecedent. }\end{array}$ & Literature review \\
\hline \multirow[t]{5}{*}{ Global treatment } & 7 & $\begin{array}{l}\text { Brambilla et al., } \\
2009 \text { [35] }\end{array}$ & $\begin{array}{l}30 \text { ( }+5 \text { dropped-out }) \\
\text { BED ( } 3 \text { groups of } \\
10 \text { patients) }\end{array}$ & 6 treatment & $14 \%$ & $\begin{array}{l}\text { Group 1: 1700-kcal diet + CBT + sertraline } \\
(50-150 \mathrm{mg} / \text { day) + topiramate } \\
(25-150 \mathrm{mg} / \text { day); group 2: diet + CBT + } \\
\text { sertraline; group 3: nutritional counselling + } \\
\text { CBT. Clinical interview and self-administered } \\
\text { tests. Binge frequency and body weight } \\
\text { decrease only in group 1. Group } 2 \text { improved } \\
\text { in depression, interpersonal relationship and } \\
\text { schizoid personality subscales. }\end{array}$ & Clinical trial \\
\hline & & $\begin{array}{l}\text { Deumens et al., } \\
2012 \text { [59] }\end{array}$ & 212 BED & 5 treatment & $14 \%$ & $\begin{array}{l}\text { Higher social embedding and higher } \\
\text { openness predict better outcomes at CBT } \\
\text { (self-administered tests). Higher depression, } \\
\text { agoraphobia and extraversion predict } \\
\text { poorer outcome. }\end{array}$ & $\begin{array}{l}\text { Prospective } \\
\text { observational study }\end{array}$ \\
\hline & & $\begin{array}{l}\text { Flukinger et al., } \\
2011 \text { [37] }\end{array}$ & 78 BED & $\begin{array}{l}4 \text { treatment; } \\
6 \text { follow-up }\end{array}$ & $36 \%$ & $\begin{array}{l}\text { Low self-esteem predicts premature treatment } \\
\text { termination. Low self-esteem experiences, low } \\
\text { global alliance, low mastery and clarification } \\
\text { experiences predict dropout in patients who } \\
\text { report discontentment with therapy as reason } \\
\text { for premature termination. }\end{array}$ & $\begin{array}{l}\text { Prospective } \\
\text { observational study }\end{array}$ \\
\hline & & $\begin{array}{l}\text { Grilo et al., } \\
2011^{1} \text { [52] }\end{array}$ & $\begin{array}{l}125 \text { obese with BED } \\
\text { (45 CBT; } 45 \text { BWL; } \\
35 \text { CBT + BWL) }\end{array}$ & $\begin{array}{l}4 \text { treatment }+12 \\
\text { follow-up }\end{array}$ & $24-40 \%$ & $\begin{array}{l}\text { At 12-month, binge-eating remission rates } \\
\text { of } 51 \% \text { (CBT), 36\% (BWL), } 40 \% \text { (CBT + BWL) } \\
\text { and mean BMI losses of -0.9\%(CBT), }-2.1 \% \\
\text { (BWL) and 1.5\% (CBT + BWL). Overall significant } \\
\text { percent BMI loss in CBT + BWL attributable to } \\
\text { BWL. Binge-eating remission associated with } \\
\text { greater percent BMI loss. }\end{array}$ & $\begin{array}{l}\text { Prospective } \\
\text { observational study }\end{array}$ \\
\hline & & $\begin{array}{l}\text { Grilo et al., } \\
2012 a^{1} \text { [44] }\end{array}$ & $\begin{array}{l}90 \text { obese with BED } \\
\text { ( } 45 \text { CBT; } 45 \text { BWL) }\end{array}$ & $\begin{array}{l}4 \text { treatment }+12 \\
\text { follow-up }\end{array}$ & $24-40 \%$ & $\begin{array}{l}\text { Rapid response ( } \geq 70 \% \text { binge reduction in } \\
4 \text { weeks) is present in } 57 \% \text { of participants } \\
(67 \% \text { CBT, } 47 \% \text { BWL) and predicts greater } \\
\text { improvements across outcomes. CBT patients } \\
\text { did comparably well regardless of rapid } \\
\text { response in binge eating and eating } \\
\text { psychopathology but not in weight loss. BWL } \\
\text { patients without rapid response failed to } \\
\text { improve further but those with rapid response } \\
\text { show greater reductions in binge frequency, } \\
\text { eating psychopathology and weight loss. }\end{array}$ & $\begin{array}{l}\text { Prospective } \\
\text { observational study }\end{array}$ \\
\hline
\end{tabular}

Binge frequency and body weight

increase only in group 1. Group 2 improved

edding and higher

(a)

(Higher depression,

poorer outcome.

Low self-esteem predicts premature treatment

At 12-month, binge-eating remission rates of $51 \%$ (CBT), 36\% (BWL), $40 \%$ (CBT + BWL) percent BMI loss in CBT + BWL attributable to ercent BMI loss. psychopathology and weight loss. 
Table 1 Summary of studies included in the review* (Continued)

2010 [36]

Zunker et al

$2010^{2}[45]$

179 BED patients

81 rapid responders

98 non rapid

responders)

Behavioral interventions, 24

psychoeducationand

psychotherapies

Balestieri et al.,

2013 [54]

98 patients (54 BED;

44 EDNOS)
2.5 weekly +8

$6.1 \%$ after monthly sessions 10 weeks, $-39.6 \%$ at 8 months

Carrard et al. 2011 [62]

74 women with BED (37 Group 1; 37 Group 2)

6 treatment +6 follow-up

$19-24,3 \%$

Castellini et al.,
793 mixed EDs (of which 283 BED)
6 treatment $+72 \quad 0 \%$ follow-up
Psychotherapy and structured self-help, mainly

$C B T$, recommended as first line treatments for $B E D$. Moderately positive effect on binges and depressive symptoms of pharmacotherapy,

manly SSRI. Weight-loss treatments demonstrated moderate binge reduction at uncontrolled studies. Combination treatments not show higher effects than single-treatment. Only weight-loss treatment show a considerable weight reduction.

Participant randomized to 3 group manual-based CBT (therapist-led, therapist-assisted, self-help). Decrease in binges during treatment predicts clinical outcome. Participants with a 15\% reduction in binges at week-one more likely to achieve remission.

Psychoeducational intervention of 10 weekly group sessions. Post-treatment patients who maintained an ED were asked to participate to 2 fortnightly sessions + monthly sessions for 8 months. At 10 weeks $30.6 \%$ of patients remitted and all patients showed significant improvements on binge frequency, BMI bulimic traits, body dissatisfaction, anxiety, depression and alexithymia. At 8 month $41 \%$ recovered from $E D$, with further reduction of binges and improvement of BMI.

Group 1: 6 months online CBT +6 months follow-up; group 2: 6 months waiting list +6 months online CBT. Regular e-mail contact with a coach during intervention. After treatment binge eating, drive for thinness, body dissatisfaction and

interoceptive awareness significantly improved. Binge episodes, overall eating symptoms and hunger also decreased. Improvements maintained at follow-up. Higher shape concern and higher drive for thinness among dropouts.

Patients evaluated with clinical interview undergo 6 months individual CBT. At 6-year follow-up, overall recovery rate was $59.2 \%$ for BED and $77.2 \%$ for subthreshold BED. Crossover rates (DSM-IV) of $8.8 \%$ from BED to $\mathrm{BN}$ and $10.9 \%$ from BN to BED. Relapse rates of $11.4 \%$ for BED and $12.1 \%$ for subthreshold-BED. Among relapsed patients who changed diagnosis $18.1 \%$ of $\mathrm{BN}$ developed BED, $18.7 \%$ of BED developed $\mathrm{BN}$ and $87 \%$ of subthreshold-BED developed BED.
Literature

meta-analysis

Prospective

observational study

Clinical tria

Clinical trial

Prospective

observational study 
Table 1 Summary of studies included in the review* (Continued)

\begin{tabular}{|c|c|c|c|}
\hline $\begin{array}{l}\text { Compare et al., } \\
2013 \text { [46] }\end{array}$ & $\begin{array}{l}189 \text { obese with BED } \\
\text { (63 EFT; } 63 \mathrm{CT} ; 63 \mathrm{DT} \text { ) }\end{array}$ & $\begin{array}{l}5 \text { treatment }+6 \\
\text { follow-up }\end{array}$ & $\begin{array}{l}27 \% \text { DT vs. } 12.7 \\
\text { EFT vs. } 0 \% \text { CT }\end{array}$ \\
\hline $\begin{array}{l}\text { Hilbert et al., } \\
2012 \text { [67] }\end{array}$ & 90 BED (45 CBT; 45 IPT) & $\begin{array}{l}5 \text { treatment, } \\
48 \text { follow-up }\end{array}$ & $\begin{array}{l}24.7 \% \text { of treatec } \\
\text { sample }\end{array}$ \\
\hline $\begin{array}{l}\text { lacovino et al., } \\
2012 \text { [43] }\end{array}$ & 27 articles & -—— & -—— \\
\hline $\begin{array}{l}\text { Wilson \& Zandberg, } \\
2012 \text { [61] }\end{array}$ & $\begin{array}{l}24 \text { articles (12 BN; } \\
9 B E D, 3 \text { EDNOS) }\end{array}$ & -—— & -—- \\
\hline $\begin{array}{l}\text { Klein et al., } \\
2012 \text { [64] }\end{array}$ & $\begin{array}{l}10 \text { women with } \mathrm{BED} \\
\text { or BN }\end{array}$ & 4.5 treatment & $50 \%$ \\
\hline $\begin{array}{l}\text { Leombruni et al., } \\
2010 \text { [53] }\end{array}$ & 297 BED patients & 2.5 treatment & $27 \%$ \\
\hline $\begin{array}{l}\text { Masheb et al., } \\
2011 \mathrm{~b} \text { [40] }\end{array}$ & $\begin{array}{l}50 \text { obese with BED } \\
(25 \mathrm{CBT}+\mathrm{ED} ; \\
25 \mathrm{CBT}+\mathrm{GN})\end{array}$ & 6 treatment & $14 \%$ \\
\hline
\end{tabular}

Patients randomized to Emotionally Focused

Therapy (EFT), Dietary Counseling (DC), and

Combined Treatment (CT). DC showed

higher dropout rate. Body weight decreased

in all three groups. Eating symptomatolog

decreased with CT and EFT. At follow-up,

$71 \%$ of CT patients and $46 \%$ in EFT had

subthreshold eating impulsivity, whereas no

participants in the DC group reached this target.

20 weekly group sessions +3 individual

sessions of CBT or IPT. Long-term BED

recovery rates of $52.0 \%$ for CBT and $76.7 \%$

for IPT. Recovery from subclinical BED 72.0\%

for CBT and $83.9 \%$ for IPT (non-significant

difference). BMI stable in both treatments.

Individual and group CBT associated with higher binge abstinence rates compared with supportive therapy and BWL. CBT guided

self-help have superior outcomes than BWL guided self-help and comparable to IPT in

patients with low additional pathology. IPT is

the only treatment with comparable long-term outcomes to CBT. Psychodynamic IPT

(additional focus on cyclical relational pattern and negative internalizations) comparable to CBT both post-treatment and at 12-month follow-up. DBT shows some promise as BED treatment, but requires further study.

Literature evidenced CBT guided self-help as a brief, cost-effective treatment for BED,

comparable with more complex interventions and not necessarily contra-indicated for patients with comorbid conditions.

DBT showed positive preliminary outcomes on binge eating and eating psychopathology.

Group psychoeducational intervention showed efficacy on eating impulsivity and related psychopathology. No significant results on weight and depression. Higher impulsivity correlates with higher drop-out rates.

Patients randomized to CBT + low-Energy-Density diet $(C B T+E D)$ or CBT + General Nutrition counseling not related to weight loss

(CBT + GN). 30\% of patients achieved at least a $5 \%$ weight loss with binge remission rates of $55-75 \%$. No significant differences among treatments. Significantly better dietary

outcomes on energy density, and fruit and vegetable consumption at CBT +ED.
Clinical trial

Retrospective study

Literature review

Literature review

Descriptive study

Clinical tria

Randomized controlled trial 
Table 1 Summary of studies included in the review* (Continued)

$2013[66]$

30 wait-list)

3 treatment
follow-up

\section{Munsch et al.,}

2012a [31]

80 obese with BED

(44 CBT; 36 BWL)

Peterson et al.,

$2009^{2}$ [63]

259 BED (69 wait-list;

67 self-help;

63 therapist-assisted

60 therapist-led)
4 treatment +12 Treatment $27.5 \%$ extended care + (CBT) $-25 \%(B W L)$ : 72 follow-up Follow-up $41 \%$ (CBT) - 28\% (BWL)

5 treatment; 12 follow-up

$26 \%$ mean

144 BED and subthreshold-BED 72 group (BT)

\section{Robinson \& Safer,} $2012^{2}$ [7]

101 BED patients

(50 DBT; 51 ACGT)

Safer et al.

$2010^{3}[65]$

101 BED patients

(50 DBT; 51 ACGT)

Safer \& Joyce,

$2011^{3}[48]$
101 BED patients

(50 DBT; 51 ACGT)
5 treatment;

36 follow-up

5 treatment

5 treatment;

12 follow-up

5 treatment;

12 follow-up
4\% DBT 33.3\% ACGT

4\% DBT 33.3\% ACGT

4\% DBT 33.3\% ACGT
Self -help based in DBT manual + six 20-min support calls. Post-treatment efficacy on binge remission, quality of life and eating psychopathology at 6-month follow-up (clinical interview + self-report).

Patients randomized to CBT or BWL group intervention. Strong outcome improvement during active treatment but worsening at follow-up, however with residual improvement at 6-year follow-up relative to pretreatment values. Comparable long-term effects between CBT and BWL. Rapid response predicts favorable outcome.

Therapist-led vs self-help CBT-based intervention Binge abstinence in $51.7 \%$ of therapist-led, $33.3 \%$ of therapist-assisted, $17.9 \%$ of self-help group and $10.1 \%$ of wait-list. No differences in abstinence rates at follow-up. Therapist-led group show more reductions in binge eating at post treatment and follow-up. Treatment completion rates higher in therapist-led $(88.3 \%)$ and wait-list (81.2\%) groups than in therapist-assisted (68.3\%) and self-help (59.7\%) groups.

Individual and group CBT (clinical interview + self-reported tests) show similar long-term response with a significant binge reduction and mild weight reduction. Lower emotiona eating and binge eating severity predict full recovery. Overweight during childhood, full blown BED diagnosis and high emotional eating predict treatment resistance.

Comparing DBT to active comparison group therapy (ACGT), patients with Avoidant Personality Disorder or earlier onset of overweight and dieting evidenced worsened outcome.

Group DBT compared to ACGT show significantly lower dropout rate.

Post-treatment binge abstinence and reduction achieved more quick DBT-BED but no difference at follow-up.

Rapid responders, especially to group DBT, show higher binge abstinence at end of treatment and 1 year follow-up and also significantly less attrition.
Randomized controlled

trial

Clinical trial

Randomized controlled trial

Prospective randomized controlled trial

Randomized controlled trial

Randomized controlled trial

Randomized controlled 
Table 1 Summary of studies included in the review* (Continued)

Schlup et al.,

2010 [58]

(40 CBT-L; 36 CBT-S)

12 follow-up

$4 \%$ (CBT-S) - 35\%

$(\mathrm{CBT}-\mathrm{L})$

Striegel-Moore

et al., 2010 [60]

123 patients (59 BED;

$3 \mathrm{BN} ; 51$ subthreshold

treatment;

BED/BN) (59 CBT-gsh;

$64 \mathrm{TAU})$

Tasca et al

2012 [41]

95 BED (48 PIP;

$47 \mathrm{~g}(B T)$

4 treatment

6 follow-up

$22 \%$

Vancampfort et al., 3 articles (211 BED 2013 [47]

women)

Vanderlinden et al., 56 obese with BED 2012 [56]

Wilson et al.,

2010 [42]

206 BED patients

64 BWL; 66 CBTgsh;

75 IPT)

Woolhouse et al.,

43 women $(31 \%$ BN;

$50 \%$ BED; $19 \%$

2.5 treatment

$23.25 \%$
7 treatment; 60 follow-up

6 treatment; 24 follow-up

7\% IPT; 28\% BWL $30 \%$ CBTgsh

subthreshold BN/BED)

Comparing long and short term CBT - 16

treatments show significant binge reductions.

At the end of active treatment, but not at

follow-up, better outcomes in CBT-L.

Treatment efficacy for rapid responders

and individuals with high dietary negative

affect differs between CBT-L and CBT-S.

CBT based guided self-help (CBT-gsh,

8 sessions) vs treatment as usual (TAU,

non-dietary primary care management).

At follow-up, CBT-gsh show greater binge

abstinence and adjustment but not weight

change.

Both group Psychodynamic Interpersonal

Psychotherapy (gPIP) and group CBT

(gCBT) improve interpersonal problems

(self-administered tests). Higher effects of

gPIP on patients with Cold/Distant

interpersonal problems and attachment avoidance.

Aerobic and yoga exercises reduce binges

and BMI. Aerobic exercise also reduces

depressive symptoms. CBT with aerobic exercise and not $C B T$ alone reduces $B M I$.

$C B B T$ with aerobic exercise is more effective on depressive symptoms than CBT alone.

Weekly group CBT improves eating behaviors, weight and psychopathology up to

3.5 years follow-up.

Comparing individual BWL, individual IPT and group CBTgsh. Both IPT and CBTgsh resulted in greater binge remission than BWL. Moderators of outcome were self-esteem and eating psychopathology (semi structured interview + self-administered tests). CBTgsh can be a first-line treatmen option, with IPT (or full CBT) suitable for patients with low self-esteem and high eating disorder psychopathology.

Mindfulness + group CBT reduces binge eating, dieting and body image dissatisfaction both at end of treatment and follow-up. Qualitative interviews with 16 patients attributed the efficacy of mindfulness to increasing self-awareness.
Randomized controlled

Randomized controlled

\section{Clinical tria}

Literature review

Prospective randomized controlled trial

Clinical tria 
Table 1 Summary of studies included in the review* (Continued)

\begin{tabular}{|c|c|c|c|c|c|c|c|}
\hline \multirow[t]{8}{*}{$\begin{array}{l}\text { Pharmacological } \\
\text { treatments }\end{array}$} & \multirow[t]{8}{*}{13} & $\begin{array}{l}\text { Arbaizar et al., } \\
2008 \text { [74] }\end{array}$ & $\begin{array}{l}5 \text { articles (528 BED } \\
\text { patients) }\end{array}$ & -—-— & -—- & $\begin{array}{l}\text { Short-term treatment with topiramate } \\
(50-600 \mathrm{mg} / \text { day) is more effective than } \\
\text { placebo in decreasing binges and weight in } \\
\text { both } B N \text { and BED. High number of withdrawals } \\
\text { and small sample sizes limit the generalizability } \\
\text { of this result }\end{array}$ & Literature review \\
\hline & & $\begin{array}{l}\text { Calandra et al., } \\
2012 \text { [71] }\end{array}$ & $\begin{array}{l}30 \text { depressed patients } \\
\text { with BED ( } 15 \text { bupropion; } \\
15 \text { sertraline) }\end{array}$ & 6 treatment & $0 \%$ & $\begin{array}{l}\text { Bupropion ( } 150 \mathrm{mg} / \text { day) and (sertraline } \\
200 \mathrm{mg} / \text { day) both reduced anxious-depressive } \\
\text { symptoms and binge frequency. Bupropion } \\
\text { more effective in reducing weight, with } \\
\text { weight loss proportional to BMl, and } \\
\text { improving sexual performances. }\end{array}$ & $\begin{array}{l}\text { Randomized controlled } \\
\text { trial }\end{array}$ \\
\hline & & $\begin{array}{l}\text { Grilo et al., } \\
2012 b \text { [55] }\end{array}$ & $\begin{array}{l}81 \text { overweight with } \\
\text { BED ( } 27 \text { fluoxetine, } \\
26 \text { CBT + fluoxetine; } \\
28 \text { CBT+ placebo) }\end{array}$ & $\begin{array}{l}4 \text { treatment; } \\
12 \text { follow-up }\end{array}$ & $28.4 \%$ & $\begin{array}{l}\text { Remission rates at } 12 \text {-month follow-up of } \\
3.7 \% \text { for fluoxetine-only, } 26.9 \% \text { for CBT + } \\
\text { fluoxetine, and } 35.7 \% \text { for CBT + placebo. } \\
\text { None of the treatments produced significant } \\
\text { changes in BMI. CBT + fluoxetine and CBT + } \\
\text { placebo did not differ from each other. }\end{array}$ & $\begin{array}{l}\text { Double blind placebo } \\
\text { controlled trial }\end{array}$ \\
\hline & & $\begin{array}{l}\text { Guerdjikova et al., } \\
2009 \text { [76] }\end{array}$ & $\begin{array}{l}51 \text { obese with BED } \\
\text { ( } 26 \text { lamotrigine, } \\
25 \text { placebo) }\end{array}$ & 4 & $44 \%$ & $\begin{array}{l}\text { Lamotrigine ( } 236+/-150 \mathrm{mg} / \mathrm{day}) \text { and } \\
\text { placebo performed similar on binge } \\
\text { reduction, eating pathology, } \\
\text { obsessive-compulsive symptoms, impulsivity, } \\
\text { and global severity of illness. Lamotrigine } \\
\text { was associated with a numerically greater } \\
\text { amount of weight loss and significant } \\
\text { reductions of glucose, insulin, and triglycerides. }\end{array}$ & $\begin{array}{l}\text { Double blind placebo } \\
\text { controlled trial }\end{array}$ \\
\hline & & $\begin{array}{l}\text { Guerdjikova et al., } \\
2012 \text { [72] }\end{array}$ & $\begin{array}{l}40 \text { BED with depression } \\
\text { ( } 20 \text { duloxetine; } \\
20 \text { placebo) }\end{array}$ & 3 & $32.5 \%$ & $\begin{array}{l}\text { Duloxetine (mean } 78.7 \mathrm{mg} / \text { day) superior to } \\
\text { placebo in reducing binge frequency, } \\
\text { weight and Clinical Global Impression-Severity } \\
\text { of Illness ratings for binge eating and } \\
\text { depressive disorders. Changes in BMl and } \\
\text { measures of eating pathology, depression } \\
\text { and anxiety did not differ. }\end{array}$ & $\begin{array}{l}\text { Double blind placebo } \\
\text { controlled trial }\end{array}$ \\
\hline & & $\begin{array}{l}\text { Blom et al., } \\
2014 \text { [69] }\end{array}$ & $\begin{array}{l}10 \text { articles (234 BED } \\
\text { patients) }\end{array}$ & -—- & - - & $\begin{array}{l}\text { Studying placebo response in BED, } 38 \% \text { of } \\
\text { patients show partial response and } 26 \% \\
\text { attain cessation. Lower baseline binge eating } \\
\text { and longer study participation associated } \\
\text { with higher response. }\end{array}$ & $\begin{array}{l}\text { Pooled analysis of } \\
\text { clinical trials }\end{array}$ \\
\hline & & $\begin{array}{l}\text { Leombruni et al., } \\
2008 \text { [70] }\end{array}$ & $\begin{array}{l}42 \text { overweight with } \\
\text { BED ( } 22 \text { sertraline; } \\
20 \text { fluoxetine) }\end{array}$ & 6 & $35.7 \%$ & $\begin{array}{l}\text { Sertraline ( } 100-200 \mathrm{mg} / \text { day) and fluoxetine } \\
(40-80 \mathrm{mg} / \text { day) show similar efficacy on } \\
\text { binge frequency, weight loss and } \\
\text { psychopathology. Results were maintained } \\
\text { by responders over } 24 \text { weeks. }\end{array}$ & $\begin{array}{l}\text { Randomized double } \\
\text { blind controlled trial }\end{array}$ \\
\hline & & $\begin{array}{l}\text { Leombruni et al., } \\
2009 \text { [73] }\end{array}$ & $\begin{array}{l}45 \text { BED fullcriteria } \\
\text { or subthreshold }\end{array}$ & 3 & $31 \%$ & $\begin{array}{l}\text { Duloxetine (60-120 mg) reduces binges, } \\
\text { eating impulsivity, depression, weight, } \\
\text { BMl and clinical global impression. }\end{array}$ & Clinical trial \\
\hline
\end{tabular}


Table 1 Summary of studies included in the review* (Continued)

\begin{tabular}{|c|c|c|c|c|c|c|c|}
\hline & & $\begin{array}{l}\text { Marazzitti et al., } \\
2012 \text { [75] }\end{array}$ & -—-- & - - & -—- & $\begin{array}{l}\text { Topiramate (25-1400 mg/day) and zonisamide } \\
\text { (100-600 mg/day) seem to suppress appetite } \\
\text { and increase eating control, leading to } \\
\text { BMl reduction }\end{array}$ & Literature overview \\
\hline & & $\begin{array}{l}\text { McElroy et al., } \\
\text { 2011a [77] }\end{array}$ & $\begin{array}{l}40 \text { BED (20 acamprosate; } \\
20 \text { placebo) }\end{array}$ & 2.5 & $38 \%$ & $\begin{array}{l}\text { Acamprosate ( } 999-2997 \mathrm{mg} / \text { day) improves } \\
\text { binge frequency, obsessive-compulsiveness, } \\
\text { food craving and quality of life. }\end{array}$ & $\begin{array}{l}\text { Double blind placebo } \\
\text { controlled trial }\end{array}$ \\
\hline & & $\begin{array}{l}\text { Mc Elroy et al., } \\
2011 b \text { [78] }\end{array}$ & $12 \mathrm{BED}$ & 4 & $41.6 \%$ & $\begin{array}{l}\text { Sodium oxybate (mean } 7.1 \mathrm{~g} / \text { day) reduces } \\
\text { binge frequency, eating pathology, } \\
\text { obsessive-compulsive symptoms, food } \\
\text { cravings and weight. }\end{array}$ & Clinical trial \\
\hline & & $\begin{array}{l}\text { McElroy et al., } \\
2012 \text { [68] }\end{array}$ & 22 articles & -—- & -—- & $\begin{array}{l}\text { SSRIs are the most studied drugs effective on } \\
\text { binge eating and psychiatric and weight } \\
\text { symptoms. However most weight reductions } \\
\text { would not be considered clinically significant. } \\
\text { Duloxetine is effective on binge eating, } \\
\text { weight loss and depressive symptoms. } \\
\text { Reboxetine showed preliminary reductions in } \\
\text { binge frequency and BMI. Topiramate is useful } \\
\text { in BED with obesity, decreasing weight and } \\
\text { obsessive-compulsive eating pathology as well } \\
\text { as trait impulsivity. Orlistat in combination } \\
\text { with CBT or dietary therapy, enhances weight } \\
\text { loss and reduces binge eating. Zonisamide, } \\
\text { naltrexone (high doses), stimulants, and } \\
\text { glutamate-modulating agents show promises } \\
\text { for BED treatment. Data are not sufficient to } \\
\text { recommend pharmacotherapy as single first-line } \\
\text { therapy, however drugs plays an important } \\
\text { role in BED management. }\end{array}$ & Literature review \\
\hline & & $\begin{array}{l}\text { Reas \& Grilo, } \\
2008 \text { [38] }\end{array}$ & 14 articles (1279 patients) & - - & -—- & $\begin{array}{l}\text { Pharmacotherapies have a clinical significance } \\
\text { over placebo on binge remission and weight } \\
\text { loss (statistically but not clinically significant). } \\
\text { No data on long-term effects. Combining } \\
\text { medications with psychotherapy failed to } \\
\text { enhance outcomes. Promising findings, albeit } \\
\text { modest, reported for orlistat/topiramate + } \\
\text { CBT/BWL. Limited utility of SSRI. Need for } \\
\text { additional large and longer studies. }\end{array}$ & Literature review \\
\hline \multirow[t]{2}{*}{ Surgical interventions } & 4 & $\begin{array}{l}\text { Ashton et al., } \\
2011 \text { [84] }\end{array}$ & $\begin{array}{l}128 \text { bariatric surgery } \\
\text { candidates with } \\
\text { binge eating }\end{array}$ & 12 follow-up & -— & $\begin{array}{l}\text { Positive responders to a brief CBT } \\
\text { intervention targeting binge eating lost } \\
\text { more weight both at } 6 \text { months and } \\
12 \text { postoperatively. }\end{array}$ & Longitudinal study \\
\hline & & $\begin{array}{l}\text { Beck et al., } \\
2012 \text { [83] }\end{array}$ & $\begin{array}{l}45 \text { bariatric surgery } \\
\text { patients }\end{array}$ & 24 follow-up & $\begin{array}{l}33 \% \text { of eligible } \\
\text { patients }\end{array}$ & $\begin{array}{l}\text { Binge eating and ineffectiveness } \\
\text { (self-administered tests) correlate with } \\
\text { lower weight loss after surgery. }\end{array}$ & Retrospective study \\
\hline
\end{tabular}


Table 1 Summary of studies included in the review* (Continued)

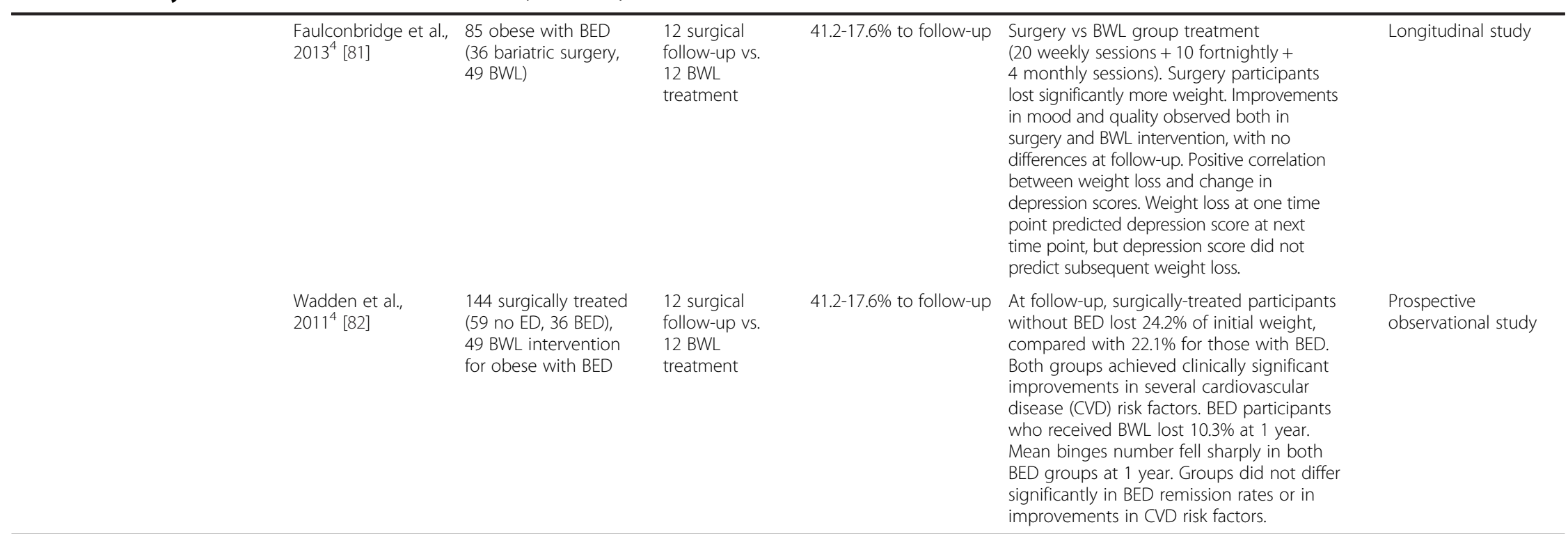
the table.

*Studies published from January 2008 to May 2014 and concerning adult patients with BED. Re
${ }^{* *}$ Description of the trial upon which the study is based has been reported elsewhere [85].

**Description of the trial upon which the study is based 
The concept of binge eating as "overeating without compensatory behaviors" was introduced by Stunkard in 1959, and structured in the Nineties by Fairburn and Spitzer as specific syndrome, mentioned in DSM-IV-TR as a nosologic entity needing future definition [24]. Due to an intense research activity providing solid evidence on the differences between BED and Bulimia Nervosa (BN), obesity and other ED-NOS [22,25], DSM-5 has recently recognized BED as an autonomous disease, maintaining diagnostic criteria which are consistent with the previous edition, but reducing both frequency of the binging episodes and duration of eating behaviors required to make the diagnosis [1].

In addition to diagnostic criteria included in DSM that have proved clinical relevance and diagnostic efficacy in several studies [22,26], also other psychopathologic basic features have been outlined as relevant for treatment planning and outcome. Overvaluation of shape and weight is one of these conditions. It is present in $60 \%$ of BED patients, a level which is significantly higher than in non-BED obese patients, even though it is lower than in $\mathrm{AN}$ and $\mathrm{BN}$, where it is nearly universal [27]. Even if this feature is present only in a subgroup of BED patients, and so it is not included among the official diagnostic criteria, it is related to higher psychosocial impairment and worse quality of life [27]. BED patients frequently refer to a constant polarization of thoughts on weight control, diet and binge-avoidance, showing worst eating control, higher fear of weight gain, and higher body-shape dissatisfaction than non-BED obese individuals, even though lower than in BN subjects $[16,21,25]$. Overvaluation of shape and weight can be thus considered either a diagnostic specifier or a dimensional severity rate, with a primary relevance for diagnosis, treatment choice, global impairment and outcome, and it can also be considered as a specific target for psychological therapies $[10,27,28]$.

Also food intake patterns are clinically important in BED, as showed by the pathogenic model which has been proposed for this disorder - inspired to the one proposed by Fairburn and Cooper for BN. According to this model, low self-esteem, body image-related, generates anxiety and negative emotions resulting in excessive diet restrictions, in turn triggering bingeing [29]. Obese individuals with BED may lack effective strategies for managing negative emotions, and it has been hypothesized that eating is undertaken as a strategy to regulate or change negative emotions [30]. Recent studies, however, describe binge eating in BED as the possible result of an immediate breakdown of emotion and impulse regulation caused by sudden increases of negative affect and tension, and/or rapid decrease of positive affect. Instead, it is unlikely that such behavior is consequent to gradual accumulation of negative mood and subsequent immediate relief as observed in $\mathrm{BN}$ [31]. Therapeutic implications of these findings are represented by the development of response-prevention strategies, such as the acceptance of stressful events or the disclosure of mental states. In contrast the suppression of unwanted behavior during of high mental load may increase the probability of bingering behavior [31].

In BED patients, daily distribution of food intake shows peculiarities, unrelated to mood fluctuations, which should be taken into account to process better dietary and behavioral strategies to manage symptoms and achieve therapeutic goals [32]. In fact, in BED patients they have been evidenced significantly more atypical eating behaviors, like dietary restraint or morning under-eating, or recurrent overeating patterns like eating double meals, or nocturnal eating and snack consumption $[18,32]$. On the other hand, more frequent breakfast consumption correlate with lower BMI and more frequent meal consumption with reduced binge eating [32].

The majority of binge episodes typically occur in less than 2 hours, with a clinical and psychopathological importance which is related to objective food intake [33]. Loss of control is a core feature associated with higher depression, higher body dissatisfaction and poorer related quality of life [33]. The peculiar food choice that patients make during binge episodes - e.g. fats, carbohydrates, sweets and snacks, - has been related to the hypothesis of a "hedonic deprivation", were eating impulsiveness can be triggered by restrictions on palatable foods during everyday life, even if at more recent findings the presence of this clinical feature seems controversial [33].

Linked to neurobiological mechanisms similar to those of substance abuse, also "food dependence" is an important correlate of this finding, with dopamine, serotonin, and endogenous opioids systems playing a role in this regard [16]. Patients with BED show an increased reward sensitivity towards food and increased rash-spontaneous behavior, thus shaping a phenotype of obesity with increased impulsiveness which should be identified and focused by specific psychological or pharmacological treatment [16]. Recent studies underline indeed the importance of genes on eating habits, identifying a heritable component of medium-high importance, referred to the whole category of ED and with a gender-independent transmission [34].

Regarding to psychopathological peculiarities and clinical implications, BED should be also differentiated from other obesity-related eating patterns characterized by eating impulsiveness, not yet recognized as autonomous syndromes but in a number of cases present in those affected by BED [32]. Some these conditions are snacking (introduction of small amounts of food throughout 
the day), emotional overeating (eating in response to intense emotional states), and selective cravings (intense desire and consuming of specific foods, e.g. sweet eating), that should be considered as subtypes of binge-eating; however, their clinical implications have to be defined yet $[25,30,31]$.

\section{Treatment}

\section{Multidisciplinary sequential approach}

The treatment of BED, as for EDs in general, is influenced by his etiological background, constituted of a complex interaction of heritable, psychological and environmental factors that should be taken into account in treatment planning [23,35]. Treatment choices should then be multidisciplinary, suited to cope with symptoms and comorbidities and also with the high drop-out rates and the low maintenance of achieved results typical of this disease [36,37]. Hallmarks of BED are in fact low self-esteem experiences, weak therapeutic alliance, low mastery and clarification experiences, in turn predicting treatment dissatisfaction with and early discontinuation of care [37]. To deal adequately with these features and with the different core psychopathologic traits, the therapeutic setting should be flexible and considering exhaustively psychological and physical impairments $[23,35]$. Moreover, the decision to seek treatment should be preceded by enhancing patients' motivation on their condition [23]. The therapeutic project should be tailored on the patient in accordance with protocol recommendations and it should be frequently revised, on the basis of the clinical needs [23]. Literature evidences concerning the combination of different treatment strategies at the same time are weak $[35,36,38,39]$, instead it seems more promising to provide stepped-care treatments with rising levels of intervention intensity tailored on disease severity [40-43].

Primary goal of BED treatment is to achieve abstinence from binge eating, and afterward a sustainable weight loss $[44,45]$. Nevertheless treatment should also target the increase and maintenance of motivation, the education to healthier eating and life styles, the modification of dysfunctional thoughts and habits, the increase of insight and abilities to deal with conflicts and negative emotions, the treatment of physical and psychiatric comorbidities and relapse prevention $[23,36,43,46]$. The therapeutic program should promote a stable reduction of caloric intake and a permanent maintenance of healthier eating and lifestyle habits, including instructing patients to self-monitor their symptoms [36,43]. More encouraging results can be obtained indeed with patients trained to manage autonomously symptoms, mood fluctuations, anxiety and stress levels $[43,46]$. This training seems to be helpful in making the patients able to recognize their needs, modify their thinking style, and facilitate not only their cognitive but also their experiential and intuitive learning $[36,43,46]$. To enhance efficacy on weight loss, which is not a primary outcome of BED treatment but a factor associated with consistent impairment and comorbidity, some evidences support the association of pharmacological and psychotherapeutic treatments to behavioral interventions, based on weight and diet monitoring, and borrowed by general obesity management [35,36,38,40,47].

It can be useful to set an adequate treatment plan as soon as possible, because early responses to treatment are important from a prognosis standpoint $[43,45,48]$. That can be favored by treatment specificity and stepped-care treatments, providing periodic re-evaluations addressing non-responders to more specialized interventions [41-43].

Binge abstinence should be pursued at the very beginning of treatment, also because the achievement of this goal per se in some cases leads to significant weight loss [44]. Nevertheless in most cases treatment should not target weight loss at first, but weight stabilization $[44,49]$. Some studies in fact show frequent and substantial weight gain one year prior treatment seeking, providing an important element to interpret the modest weight losses typically reported in literature $[49,50]$. Also weight regain is a critical target for BED patients, who report marked weight fluctuations and spend much time trying to lose weight [50]. The poor weight loss showed in literature studies may than be re-interpreted at the light of a successful weight stabilization, and an effective prevention of further weight regain $[49,50]$.

\section{Behavioral interventions}

Behavioral treatments (BWL), focused on diet and lifestyle modification, and borrowed by obesity treatment, have frequently been proposed as useful basic interventions for BED treatment that showed some appreciable results which are comparable to more complex therapies, in patients with low associated psychopathology $[44,51]$.

Diet therapy is essential to promote weight loss, and for this reason it is object of great attention among BED patients who are characterized by high body dissatisfaction [21] and higher overvaluation of body weight and shape, which generally represent negative outcome predictors [10]. Moreover it should be reminded that, even if body weight is not directly linked with disease severity, it is strictly correlated with several medical comorbidities [4]. Furthermore, body weight heavily influences perceived wellness, mood and self-esteem in those affected by BED and, consequently, binge vulnerability itself $[27,18]$. On the other hand binge episodes are recurrently triggered by excessive dietary restraint which can be enacted by BED subjects to reduce body weight faster $[18,29]$. Therefore, prescribed caloric restrictions 
in BED should be moderate, and a normal or hypocaloric diet seems to be the best strategy to prevent bingeing $[40,46]$. Weight loss anyway should be pursued only after binge reduction or stabilization and the attempt to lose considerable weight in a short time should be discouraged, because of the increased risk of weight regain $[49,51,52]$. Poor compliance to diet should not be blamed but it should be addressed instead when planning the nutritional scheme, because only its management could make it possible to reach a stable control over eating behaviors [40]. It is recommended not to totally exclude any food choices; it could be more useful instead to encourage patients to moderate their food intakes according to individual needs [40].

Physical activity, coupled to a balanced diet, is another basic factor for weight loss, both for its direct action on fat consumption and its inhibitory action on excessive food intake [47]. It also helps maintaining goals reached with diet, and it improves mood and general health, lowering clinical comorbidities of BED [47]. However, due to frequently compromised health conditions of BED patients, physical activity should be established gradually and under close medical supervision [47]. In conclusion, it must be anyhow underlined that, even if BWL therapies have showed in some studies a relevant usefulness, especially on weight loss $[35,36,44,52]$, their efficacy in BED remission is lower than more specific intervention like psychotherapies, and that their dropout rates are higher $[43,46,52]$.

\section{Psychoeducational interventions}

Psychoeducational treatments for BED are purposed to inform patients about different aspects and correlates of their disease, in order to promote a deeper comprehension of their condition and thus to increase the possibilities to manage it $[53,54]$. These interventions give information about core topics like the factors that predispose, trigger and maintain eating impulsiveness, negative effects of overweight and unbalanced or restrictive diets, and most effective methods of weight regulation [53]. Treatments are focused on plain symptoms explanation, without adopting strategies to influence unconscious or cognitive maintaining factors at a deep level, unlike to what occurs in psychotherapies $[53,54]$.

Advantages of these treatments are that they can be administered by low-specialized personnel, they can be easily manualized, and they can be structured in weekly group meetings of limited duration [53]. Patients are taught to self-monitor food intake and are informed about factors that trigger binges and about correct lifestyles, sustainable in time [53,54]. They are also explained the pathogenic mechanisms of the disease and about strategies suitable to establish a stable change. Interventions are focused on lifestyle modification to promote a general improvement of health and quality of life, rather than on weight loss itself $[53,54]$.

These interventions have showed a preliminary efficacy on binge reduction and eating impulsivity [53,54], even if effects on body dissatisfaction, anxiety, depressive symptoms and weight loss are still controversial [54]. Among patients who undergo this kind of intervention, higher eating impulsivity correlates with higher drop-out rates, and this suggests that more specific and intensive intervention should be suitable for patient with heavier psychopathology [53].

Considering these preliminary findings, psychoeducational interventions could constitute useful baseline therapies that constitute a useful starting point for more complex treatments, and that can show efficacy comparable to more complex interventions on less severe cases. Studies with randomized control groups, are still needed to support this recommendation [53].

\section{Psychotherapies}

According to literature data, also with regards to systematic reviews and meta-analysis, psychotherapies are the most validated and effective treatments for BED $[36,38,43]$.

Cognitive-Behavioral Therapies (CBT) are the most evaluated and developed psychological intervention for treating BED $[36,38]$. The focus is the etiological basis of bingeing and its relation with a self-esteem excessively dependent form body shape $[10,38]$. The most widely used CBT models are adaptations of those developed for $\mathrm{BN}$, paying close attention to weight loss and taking into account the lower restriction levels and the lower cognitive distortions of BED compared to $\mathrm{BN}[38,43]$.

CBT is a practical and adaptable intervention, with setting and duration that can be tailored on clinical needs and the possibility of being carried out independently or in combination with other pharmacological or BWL approaches [36,38-40,47]. Anyway evidences supporting combination treatment are still limited and controversial, while CBT have yet showed high efficacy when administered alone, with BED remission rates around $50-60 \%[9,52,55]$. Even if in BED CBT failed to show higher immediate binge reduction when compared to BWL interventions at short-time observations, it seems to overcome these therapies especially over long periods of time, improving quality of life, and reducing drop-out rates $[44,52]$. Long term effects of CBT approaches include, in fact, a gradual normalization of eating patterns and reduced relapse occurrence, these effects are coupled with the improvement of disinhibition, hunger, negative feelings and perceived global health $[51,56,57]$. Unfortunately, evidences about effects on weight reduction are still limited and of unclear clinical significance $[9,36,52]$. Also data about advantages of 
coupling BWL interventions targeting weight loss still needs further deepening $[40,52]$. Individual or group setting have showed a similar efficacy, maintained at 3 years follow-up [43,57]. Instead long-term versus short-term interventions have showed comparable results on patients with favorable outcome predictors, but it was evidenced an higher efficacy of long-term treatment in patients with higher psychopathology [58].

Among outcome predictors, literature data have showed a consistent importance of a rapid response to treatment, of lower overeating frequency, and of lower general psychopathology levels, but also of higher social embedding and higher openness [44,59].

CBT-based treatments have showed their usefulness also when administered in self-help setting, thus offering another valid first-line treatment option which is more efficient than treatment as usual [60], superior to BWLbased self-help models [43], and without contraindications for patients with comorbid conditions [61]. From a cost-effectiveness standpoint self-help interventions constitute a valid first-line option while more specific therapies like IPT or CBT could be used in a more specific way for patients with higher eating psychopathology and lower self-esteem [43]. Self-help interventions can be guided by either therapists trained in EDs (who can run all sessions or only some), or not ED-specialized therapists or managed by patients only $[62,63]$. The presence of a trained therapist who leads the group sessions gives a better short-term outcome and less group contrast, but significant differences have not been showed so far as regards outcomes between guided and self-help groups at follow-up [62,63]. Some preliminary studies have also evaluated the efficacy of Internet guided selfhelp programs, but their efficacy is still debated [62].

Dialectic-Behavioral Therapy (DBT) is another psychotherapeutic approach that has proved its efficacy in BED; it is more focused on emotion regulation and stress tolerance than CBT [43]. This therapy showed to be effective in binge reduction and in lowering concerns about food and body shape similarly to CBT, but it has not provided clear results on weight loss, depression, or anxiety $[64,65]$. It seems to be effective also when negative outcome predictors occur as earlier age at binges onset and higher personality disturbances $[7,48]$. Some preliminary findings show DBT to be effective also when administered as a self-help intervention, a suitable lowintensity treatment option for BED [66].

Another evidence-based psychological treatment is Interpersonal Psychotherapy (IPT). This technique focuses on personal relations and role transitions that could have a predisposing and maintaining role in EDs, in order to achieve better social interactions and to cope with interpersonal conflicts [41-43]. Even if it doesn't focus directly eating symptoms, it can be useful because it targets a specific area of impairment in BED patients [42]. This disease in fact often emerges in adolescence [4], in a context of interpersonal and maturation difficulties, and its maintenance over the years can be related to dysfunctional relational styles that triggers depression, anxiety, and anger feelings in turn underlying eating impulsiveness [11]. It has been hypothesized that IPT, also administered in a psychodynamic framework, with additional focus on cyclical dysfunctional relational patterns, could be particularly effective on individuals for whom negative moods act as major triggers for bingeing or with cold/distant attachment style [41]. It appears in any case effective on depression and psychosocial discomfort $[41,43]$. It has been observed that CBT and IPT have comparable efficacy in binge reduction, both at the end of therapy and at one-year follow-up, with a significant reduction of psychiatric comorbidities and in some cases a significant decrease in body weight. Therapeutic results are stable at a 4-year follow-up $[67,42,43]$.

All in all, psychotherapeutic approaches to BED, mostly based on CBT models, are useful first-line treatments, even more than pharmacological approaches $[36,43]$.

\section{Pharmacological treatment}

Pharmacological therapy in BED is specifically focused on the reduction of eating impulsiveness, binges and negative feelings, constituting a co-cause and a complication of eating symptoms. It has been noticed a statistically significant drug action on short-term binge remission and also on weight loss, although this does not hold significant at longer follow-up $[36,38]$. Unfortunately, few data exist on long-term efficacy of pharmacotherapy as stand-alone treatment for BED, and in some studies combined treatment of drugs and psychotherapy interventions failed to enhance outcome significantly [55,35]. Most treatment options currently used in BED have at first demonstrated their efficacy on binge reduction in $\mathrm{BN}$, but non-psychoactive drugs, borrowed from obesity treatment, are also in use in selected cases or in combination with other treatments like psychotherapies [68].

As an additional element supporting the specificity of BED diagnosis, it is noteworthy that psychopharmacological therapy showed higher efficacy in BED than in non-BED obese population and that placebo response was consistent with the one observed in other major psychiatric diseases [69].

Antidepressants are the most widely studied and applied medications in BED treatment, showing efficacy on eating impulsiveness and eating and general psychopathology, but also on anxiety and depressive symptoms, with supposed secondary positive effects on eating impulsiveness due to lowering of negative affects that trigger binges [36,38]. 
In any case it is recommended to use compounds showing side effects on weight and hunger, and it is better to choose pro-anorectic antidepressants molecules to improve treatment compliance. It is for this reason that tricyclic antidepressants are not commonly used in EDs, while selective serotonin reuptake inhibitors (SSRIs) are preferred given their anti-impulsive action [68]. On the other hand, when eating impulsiveness is not related to a specific psychopathology, it is possible to evaluate in selected cases the use of medications that act directly on hunger regulation and food absorption, without influencing mood [36].

SSRI at high doses have showed efficacy on binge reduction and associated psychopathology, with some limited evidences of effectiveness on weight loss, which are of questionable clinical significance $[38,68]$. Even if differences in long-term action among SSRI still have to be clearly established, fluoxetine is the most widely studied and prescribed because of its registration for $\mathrm{BN}$ [70]. It proved significant efficacy above placebo on binge reduction, weight loss and mood improvement $[69,70]$, but uncertain clinical relevance and consistently lower effects than CBT, also in combination treatments [55,70]. Sertraline and fluvoxamine have showed similar results to fluoxetine, while citalopram and paroxetine are scarcely implied because of their side-effects on hunger and weight gain $[68,70,71]$.

Duloxetine in some initial studies was reported to reduce hunger and binges and promote weight loss [72,73], even the current body of evidence is still lacking [68].

Reboxetine showed significant reductions in binge frequency and BMI in a small preliminary open-label trial of 12-week [67].

Bupropion showed effectiveness on binge eating, anxiety, and depressive symptoms in a single study, with better efficacy than sertraline on sexual side-effects and weight loss [71].

Among anti-epileptic drugs, topiramate reduced hunger, promotes weight loss, and can obtain a significant reduction in daily and weekly binge episodes and impulsivity. Nevertheless, it has not showed efficacy on psychopathological distress or depressive symptoms, while its results on weight loss are still debated [68,74,75]. Lamotrigine showed preliminary efficacy on weight loss and metabolic dysfunction but without results on general and eating psychopathology, and global severity of illness [76]. Also zonisamide seems to be able to suppress appetite and increase eating control, leading to BMI reduction $[75,68]$.

Psychostimulants like atomoxetine, naltrexone and glutamate-modulating agents seems to be promising treatments, acting on binge reduction and weight loss when compared to placebo [68].
Acamprosate was associated at endpoint analysis with improvements on binge frequency, food craving and quality of life compared to placebo [77]. Sodium oxibate, in a small sample without control group, show reductions of binge episodes, related psychopathology, and also weight loss [78].

In conclusion, current literature data evidence still unclear efficacy of pharmacological treatments for BED. Nevertheless they are widely applied in clinical practice and play an important role in BED management [68]. Even though these treatments produced a significant reduction of binges and eating impulsiveness, and in some cases also weight losses, clinical relevance of these modifications is still doubtful and limited by small sample sizes, high dropout rates, and short follow-up times $[38,68]$. Also the usefulness of pharmacotherapy as association treatment, with the purpose to enhance effects of BWL or psychotherapies, is still highly unclear, with scarce data and discordant findings at support $[35,36,38,68]$.

\section{Surgical interventions}

Bariatric surgery is a recommended treatment for severe obesity (BMI $\geq 40$ or BMI $\geq 35$ with comorbid conditions) according to current guidelines [79], while it is not mentioned among evidence-based BED treatments [80]. However obese individuals with BED frequently experience weight-related impairments in mood and quality of life, which improve with weight loss [19]. This improvement of wellness and quality of life acts as a protective factor against binge vulnerability, making bariatric surgery a useful option in severe obesity linked to BED [81]. The high disability linked to BED itself, coupled with the difficulty to achieve a stable weight loss with traditional behavioural interventions, causes an elevate BED prevalence in surgery candidates, ranging from 5\% to 50\% [82]. On the other hand, an ED diagnosis was once considered a major contraindication to bariatric surgery. This limitation has been reduced over time and bariatric surgery interventions can now be suitable for selected BED patient, even if the extent of weight loss depends on the presence of binge episodes after the intervention [83].

Faulconbridge and coworkers [81] explored the effects of bariatric surgery in BED patients with severe obesity, trying to enlighten if observed improvements are due to weight loss itself or to additional aspects of treatment, such as therapeutic support or acquisition of cognitivebehavioral skills. They found significant improvements in mood and quality of life at follow-up both in patients who undergo surgery and in controls enrolled in a BWL intervention, but they evidenced no differences between the groups at month 12. Nevertheless, bariatric surgery showed a significantly higher efficacy on weight reduction [81]. 
Wadden and coworkers [82] found no relevant differences in post-surgical weight loss between patients with and without BED, higher than weight loss obtained with lifestyle modifications at 1 year follow-up. The mean number of binge eating days fell sharply both with surgery and with BWL interventions [82].

Nevertheless, due to the required changes in patients' lifestyle and the high economic costs of bariatric surgery, candidates should be carefully screened. These treatments should then be proposed after a careful evaluation of psychological conditions, and a psychiatric and psychological assessment before and after surgical intervention is recommended. In fact, bariatric surgery or lifestyle modification treatments led to comparable results on mood and quality of life at the 1-year follow-up [84]. To achieve good outcome it is fundamental to provide the patient with a framework of nutritionalmetabolic and psychological rehabilitation, focused on empowering and stimulating an active and informed collaboration [84]. In the first months after surgery, patients with BED who present a high gastric capacity before intervention can show an initial weight loss even higher than usual and complete binges remission [82]. However binge behaviors tend to resume partially after 12 months follow-up [82]. Binge recurrence may occur when patients learn to manage their new condition, and to circumvent eating limitations caused by the intervention - e.g. replacing classical binge episodes with great caloric intakes in liquid or semi-liquid forms $[82,84]$.

It is noticeable from these data that a stable binge control, obtained with pharmacological o psychological intervention, should be a primary outcome to be pursued in BED patients that undergo bariatric surgery [83]. It predicts better prognosis which is frequently not significantly different from that of non-BED obese individuals $[81,82,84]$.

\section{Conclusions}

Despite its recent inclusion in DSM-5 as an autonomous disease, further research is needed on BED diagnosis and treatment strategies, through larger samples and longer follow-up times [36]. Although present diagnostic criteria has showed their empirical consistency other core psychopathologic features like body and weight overvaluation may be of clinical and prognostic relevance [27]. Binge stability and spontaneous remission rates should be better explored [9], deepening the identification of prognostic factors able to address treatment choices and to favor more specific and cost-effective interventions [36,37]. Also the importance of comorbidities and weight maintenance in treatment adherence and remission should be extensively investigated because of its influence on prognosis and treatment [18].
Multidisciplinary treatment choices seems to emerge as the best treatment strategy for long-term management of this disease, with primary goals on binge abstinence and at a second time a sustainable weight loss $[44,45]$. Nevertheless treatment should also target secondary outcomes as the increase and maintenance of motivation, the reduction of drop-out rates and the management of relapses [43,46]. Further studies are however required to enlighten most promising treatment combinations, considering evidences of limited usefulness of combining different treatments at the same time $[35,36,38,39]$. Stronger literature support stepped-care treatments, with a rising intensity of intervention tailored on disease severity [40-43].

Psychotherapeutic approaches to BED, mostly based on CBT models, are recommendable as first-line treatments with the wider evidences of efficacy also at longterm follow-up, but still unclear results on weight loss [36]. Otherwise simpler and cheaper interventions like BWL treatments, psychoeducational interventions and self-help treatments have showed significant efficacy in patients with lower disease severity and less comorbidity $[43,44,53]$.

Drug therapy, especially SSRIs can be useful in lowering eating impulsivity and improving psychiatric comorbidities [36]. Unfortunately, long-term efficacy of pharmacotherapy as a stand-alone treatment for BED needs further research, as well as long-term effects of integrated treatment combining drugs and psychotherapy $[36,38]$.

Even if bariatric surgery is not a recommended treatment for BED according to current guidelines [79], its clinical relevance in BED coupled with severe obesity deserves more careful clarifications [80].

In summary, even if literature data about BED diagnosis and treatment are gradually deepening and improving in detail and significance, further studies, especially literature review and meta-analysis, are still required with major regard to long term outcomes, stepped care treatment, improving of weight loss (also with surgery treatment) and lowering dropout rates.

\section{Abbreviations}

BED: Binge Eating Disorder; EDs: Eating disorders; ED-NOS: Eating Disorder not Otherwise Specified; BMI: Body mass index; AN: Anorexia nervosa; BN: Bulimia nervosa; DSM: Diagnostic and Statistical Manual of mental disorders; CBT: Cognitive behavioral therapy; BWL: Behavioral Weight Loss; DBT: Dialectic-Behavioral Therapy; IPT: Interpersonal Psychotherapy; SSRI: Selective Serotonin Reuptake Inhibitors; NARI: Noradrenalin and Adrenaline Reuptake Inhibitors; SNRI: Serotonin and Noradrenalin Reuptake Inhibitors.

\section{Competing interests}

The authors have no financial competing interest to disclosure. As regards non-financial competing interests, since SF is a member of the editorial board of the journal, he specifically asked not to be involved in editorial process of this manuscript. 


\section{Authors' contributions}

SF, GAD and FA have conceived this work. SF, GAD and FA supervised the manuscript in all phases of its preparation and critically revised the paper. FA and LO have managed the identification of search strategy, collection and selection of the articles and English translation, as well as reviewing and drafting of the paper. All authors read and approved the final manuscript.

\section{Acknowledgements}

We thank Dr Enrica Marzola for her help in the language revision of the manuscript. None else than the authors was enrolled in the preparation of this paper.

\section{Received: 18 July 2014 Accepted: 18 March 2015}

\section{Published online: 03 April 2015}

\section{References}

1. American Psychiatric Association. Diagnostic and statistical manual of mental disorders. 5th ed. Washington, DC: American Psychiatric Publishing 2013.

2. Amianto F, Lavagnino L, Abbate-Daga G, Fassino S. The forgotten psychosocial dimension of the obesity epidemic. Lancet. 2011;378:e8.

3. Wang YC, McPherson K, Marsh T, Gortmaker SL, Brown M. Health and economic burden of the projected obesity trends in the USA and the UK. Lancet. 2011;378:815-25.

4. Kessler RC, Berglund PA, Chiu WT, Deitz AC, Hudson Jl, Shahly V, et al. The prevalence and correlates of binge eating disorder in the World Health Organization World Mental Health Surveys. Biol Psychiatry. 2013;73(9):904-14.

5. Hudson JI, Coit CE, Lalonde JK, Pope HG. By how much will the proposed new DSM-5 criteria increase the prevalence of binge eating disorder? Int J Eat Disorders. 2012;45(1):139-41.

6. Trace SE, Thornton LM, Root TL, Mazzeo SE, Lichtenstein P, Pedersen NL, et al. Effects of reducing the frequency and duration criteria for binge eating on lifetime prevalence of bulimia nervosa and binge eating disorder: implications for DSM-5. Int J Eat Disord. 2012;45(4):531-6. doi:10.1002/eat.20955.

7. Robinson AH, Safer DL. Moderators of Dialectical Behavioural Therapy for Binge Eating Disorder: Results from a Randomized Controlled Trial. Int J Eat Disord. 2012;45(4):597-602. doi:10.1002/eat.20932.

8. Peterson CB, Swanson SA, Crow SJ, Mitchell JE, Agras WS, Halmi KA, et al. Longitudinal stability of binge-eating type in eating disorders. Int J Eat Disord. 2012;45(5):664-9. doi:10.1002/eat.22008.

9. Castellini G, Lo Sauro C, Mannucci E, Ravaldi C, Rotella CM, Faravelli C, et al, Diagnostic crossover and outcome predictors in eating disorders according to DSM-IV and DSM-V proposed criteria: a 6-year follow-up study. Psychosom Med. 2011;73(3):270-9. doi:10.1097/PSY.0b013e31820a1838.

10. Grilo CM, White MA, Gueorguieva R, Wilson GT, Masheb RM. Predictive significance of the overvaluation of shape/weight in obese patients with binge eating disorder: findings from a randomized controlled trial with 12-month follow-up. Psychol Med. 2013;43(6):1335-44.

11. Fassino S, Leombruni P, Pierò A, Abbate-Daga G, Rovera GG. Mood, eating attitudes, and anger in obese women with and without Binge Eating Disorder. J Psychosom Res. 2003;54(6):559-66.

12. Carano A, De Berardis D, Campanella D, Serroni N, Ferri F, Di lorio G, et al. Alexithymia and suicide ideation in a sample of patients with binge eating disorder. J Psychiatr Pract. 2012;18(1):5-11. doi:10.1097/01. pra.0000410982.08229.99.

13. Compare A, Callus E, Grossi E. Mindfulness trait, eating behaviours and body uneasiness: a case-control study of binge eating disorder. Eat Weight Disord. 2012;17(4):e244-51. doi:10.3275/8652.

14. Blomquist KK, Ansell EB, White MA, Masheb RM, Grilo CM. Interpersonal problems and developmental trajectories of binge eating disorder. Compr Psychiatry. 2012;53(8):1088-95. doi:10.1016/j.comppsych.2012.05.003.

15. Sawaoka T, Barnes RD, Blomquist KK, Masheb RM, Grilo CM. Social anxiety and self-consciousness in binge eating disorder: associations with eating disorder psychopathology. Compr Psychiatry. 2012;53(6):740-5. doi:10.1016/j. comppsych.2011.10.003.

16. Schag K, Schönleber J, Teufel M, Zipfel S, Giel KE. Food-related impulsivity in obesity and binge eating disorder - a systematic review. Obes Rev. 2013;14(6):477-95. doi:10.1111/obr.12017.

17. Amianto F, Lavagnino L, Leombruni P, Gastaldi F, Abbate Daga G, Fassino S. Hypomania across the binge eating spectrum. A study on hypomanic symptoms in full criteria and sub-threshold binge eating subjects. J Affect Disord. 2011:133:580-3.

18. Carrard I, Crépin C, Ceschi G, Golay A, Van der Linden M. Relations between pure dietary and dietary-negative affect subtypes and impulsivity and reinforcement sensitivity in binge eating individuals. Eat Behav. 2012;13(1):13-9.

19. Peterson CB, Miller KB, Crow SJ, Thuras P, Mitchell JE. Subtypes of binge eating disorder based on psychiatric history. Int J Eat Disord. 2005;38(3):273-6

20. Folope V, Chapelle C, Grigioni S, Coeffier M, Dechelotte P. Impact of eating disorders and psychological distress on the quality of life of obese people. Nutrition. 2012;28(7-8):e7-13.

21. Bautista-Díaz ML, Franco-Paredes K, Mancilla-Díaz JM, Alvarez-Raynutrieón G, López-Aguilar X, Ocampo Téllez-Girón T, et al. Body dissatisfaction and socio-cultural factors in women with and without BED: their relation with eating psychopathology. Eat Weight Disord. 2012;17(2):e86-92.

22. Striegel-Moore RH, Franko DL. Should binge eating disorder be included in the DSM-V? A critical review of the state of the evidence. Annu Rev Clin Psychol. 2008:4:305-24. doi:10.1146/annurev.clinpsy.4.022007.141149.

23. Fassino S, Daga G, Pierò A, Delsedime N. Psychological Factors Affecting Eating Disorders. In: Porcelli P, Sonino N, editors. Psychological Factors Affecting Medical Conditions. A New Classification for DSM-V. Adv Psychosom Med. Basel: Karger; 2007. p. 141-68. 28

24. American Psychiatric Association. Diagnostic and statistical manual of mental disorders (IV ed., Text Revision). Washington, DC: American Psychiatric Publishing; 2002

25. Thomas JJ, Vartanian LR, Brownell KD. The relationship between eating disorder not otherwise specified (EDNOS) and officially recognized eating disorders: meta-analysis and implications for DSM. Psychol Bull. 2009:135(3):407-33.

26. White MA, Grilo CM. Diagnostic Efficiency of DSM-IV Indicators for Binge Eating Episodes. J Consult Clin Psychol. 2011;79(1):75-83.

27. Grilo CM, Crosby RD, Masheb RM, White MA, Peterson CB, Wonderlich SA, et al. Overvaluation of shape and weight in binge eating disorder, bulimia nervosa, and sub-threshold bulimia nervosa. Behav Res Ther. 2009:47(8):692-6.

28. Ojserkis R, Sysko R, Goldfein JA, Devlin MJ. Does the overvaluation of shape and weight predict initial symptom severity or treatment outcome among patients with binge eating disorder? Int J Eat Disord 2012;45(4):603-8. doi:10.1002/eat.20981

29. Fairburn CG, Cooper Z, Shfran R. Cognitive behaviour therapy for eating disorders: a "transdiagnostic" theory and treatment? Behav Res Ther. 2003:41(5):509-28.

30. Gianini LM, White MA, Masheb RM. Eating pathology, emotion regulation, and emotional overeating in obese adults with Binge Eating Disorder. Eat Behav. 2013;14(3):309-13.

31. Munsch S, Meyer AH, Quartier V, Wilhelm FH. Binge eating in binge eating disorder: a breakdown of emotion regulatory process? Psychiatry Res. 2012:28(195(3)):118-24

32. Masheb RM, Grilo CM, Whites MA. An examination of eating patterns in community women with bulimia nervosa and binge eating disorder. Int $J$ Eat Disord. 2011;44(7):618-24. doi:10.1002/eat.20853.

33. Wolfe BE, Baker CW, Smith AT, Kelly-Weeder S. Validity and utility of the current definition of binge eating. Int J Eat Disord. 2009;42(8):674-86.

34. Thornton LM, Mazzeo SE, Bulik CM. The heritability of eating disorders: methods and current findings. Curr Top Behav Neurosci. 2011;6:141-56.

35. Brambilla F, Samek L, Company M, Lovo F, Cioni L, Mellado C. Multivariate therapeutic approach to binge-eating disorder: combined nutritional, psychological and pharmacological treatment. Int Clin Psychopharmacol. 2009:24(6):312-7. doi:10.1097/YIC.0b013e32832ac828.

36. Vocks S, Tuschen-Caffier B, Pietrowsky R, Rustenbach SJ, Kersting A, Herpertz S. Meta-analysis of the effectiveness of psychological and pharmacological treatments for binge eating disorder. Int J Eat Disord. 2010;43(3):205-17.

37. Fluckinger C, Meyer A, Wampold BE, Gassmann D, Messerli-Burgy N, Munsch S. Predicting premature termination within a randomized controlled trial for binge-eating patients. Behav Ther. 2011:42(4):716-25.

38. Reas DL, Grilo CM. Review and meta-analysis of pharmacotherapy for bingeeating disorder. Obesity. 2008;16(9):2024-38.

39. Woolhouse $H$, Knowles A, Crafti N. Adding mindfulness to CBT programs for binge eating: a mixed-methods evaluation. Eat Disord. 2012;20(4):321-39. doi:10.1080/10640266.2012.691791. 
40. Masheb RM, Grilo CM, Rolls BJ. A randomized controlled trial for obesity and binge eating disorder: low-energy-density dietary counselling and cognitive-behavioural therapy. Behav Res Ther. 2011;49(12):821-9.

41. Tasca GA, Balfour L, Presniak MD, Bissada H. Outcomes of specific interpersonal problems for binge eating disorder: comparing group psychodynamic interpersonal psychotherapy and group cognitive behavioural therapy. Int J Group Psychother. 2012;62(2):197-218.

42. Wilson GT, Wilfley DE, Agras WS, Bryson SW. Psychological treatments of binge eating disorder. Arch gen psychiatr. 2010;67(1):94-101.

43. lacovino JM, Gredysa DM, Altman M, Wilfley DE. Psychological Treatments for Binge Eating Disorder. Curr Psychiatry Rep. 2012;14(4):432-46. doi:10.1007/s11920-012-0277-8.

44. Grilo CM, White MA, Wilson GT, Gueorguieva R, Masheb RM. Rapid response predicts 12-month post-treatment outcomes in binge-eating disorder: theoretical and clinical implications. Psychol Med. 2012;42(4):807-17.

45. Zunker C, Peterson CB, Cao L, Mitchell JE, Wonderlich SA, Crow S, et al. A receiver operator characteristics analysis of treatment outcome in binge eating disorder to identify patterns of rapid response. Behav Res Ther. 2010;48(12):1227-31.

46. Compare A, Calugi S, Marchesini G, Molinari E, Dalle Grave R. Emotionfocused therapy and dietary counselling for obese patients with binge eating disorder: a propensity score-adjusted study. Appetite. 2013:82(3):193-4. doi:10.1159/000343209.

47. Vancampfort D, Vanderlinden J, De Hert M, Adámkova M, Skjaerven LH, Catalán-Matamoros D, et al. A systematic review on physical therapy interventions for patients with binge eating disorder. Disabil Rehabil. 2013;35(26):2191-6. doi:10.3109/09638288.2013.771707. Epub 2013 Apr 17.

48. Safer DL, Joyce EE. Does rapid response to two group psychotherapies for binge eating disorder predict abstinence? Behav Res Ther. 2011;49(5):339-45. doi:10.1016/j.brat.2011.03.001.

49. Blomquist KK, Barnes RD, White MA, Masheb RM, Morgan PT, Grilo CM. Exploring weight gain in year before treatment for binge eating disorder: a different context for interpreting limited weight losses in treatment studies. Int J Eat Disord. 2011:44(5):435-9. doi:10.1002/eat.20836.

50. Masheb RM, White MA, Grilo CM. Substantial weight gains are common prior to treatment-seeking in obese patients with binge eating disorder. Compr Psychiatry. 2013;54(7):880-4. doi:10.1016/j. comppsych.2013.03.017.

51. Munsch S, Meyer AH, Biedert E. Efficacy and predictors of long-term treatment success for Cognitive-Behavioural Treatment and Behavioural Weight-LossTreatment in overweight individuals with binge eating disorder. Behav Res Ther. 2012:50(12):775-85.

52. Grilo CM, Masheb RM, Wilson GT, Gueorguieva R, White MA. Cognitivebehavioral therapy, behavioral weight loss, and sequential treatment for obese patients with binge-eating disorder: a randomized controlled trial. J Consult Clin Psychol. 2011;79(5):675-85. doi:10.1037/a0025049.

53. Leombruni $P$, Ottone L, Lavagnino L, Siccardi S, Nicotra B, Migliore F, et al. Group psychoeducational psychotherapy in Binge Eating Disorder. Minerva Psichiatr. 2010;51(3):135-44.

54. Balestrieri M, Isola M, Baiano M, Ciano R. Psychoeducation in Binge Eating Disorder and EDNOS: a pilot study on the efficacy of a 10-week and a 1-year continuation treatment. Eat Weight Disord. 2013;18(1):45-51. doi:10.1007/s40519-013-0014-2.

55. Grilo CM, Masheb RM, Crosby RD. Predictors and moderators of response to cognitive behavioural therapy and medication for the treatment of binge eating disorder. J Consult Clin Psychol. 2012;80(5):897-906.

56. Vanderlinden J, Adriaensen A, Vancampfort D, Pieters G, Probst M, Vansteelandt K. A cognitive- behavioural therapeutic program for patients with obesity and binge eating disorder: short- and long- term follow-up data of a prospective study. Behav Modif. 2012;36(5):670-86. doi:10.1177/ 0145445512439313.

57. Ricca V, Castellini G, Mannucci E, Lo Sauro C, Ravaldi C, Rotella CM, et al. Comparison of individual and group cognitive behavioral therapy for binge eating disorder. A randomized, three-year follow-up study. Appetite. 2010;55(3):656-65

58. Schlup B, Meyer AH, Munsch S. A non-randomized direct comparison of cognitive-behavioural short- and long-term treatment for binge eating disorder. Obes Facts. 2010;3(4):261-6.

59. Deumens RA, Noorthoorn EO, Verbraak MJ. Predictors for treatment outcome of binge eating with obesity: a naturalistic study. Eat Disord. 2012;20(4):276-87. doi:10.1080/10640266.2012.689207.
60. Striegel-Moore RH, Wilson GT, DeBar L, Perrin N, Lynch F, Rosselli F, et al. Cognitive behavioural guided self-help for the treatment of recurrent binge eating. J Consult Clin Psychol. 2010;78(3):312-21.

61. Wilson GT, Zandberg LJ. Cognitive-behavioral guided self-help for eating disorders: Effectiveness and scalability. Clin Psychol Rev. 2012;32(4):343-57.

62. Carrard I, Crépin C, Rouget P, Lam T, Golay A, Van der Linden M. Randomised controlled trial of a guided self-help treatment on the Internet for binge eating disorder. Behav Res Ther. 2011;49(8):482-91. doi:10.1016/j. brat.2011.05.004

63. Peterson CB, Mitchell JE, Crow SJ, Crosby RD, Wonderlich SA. The efficacy of self-help group treatment and therapist-led group treatment for binge eating disorder. Am J Psychiatry. 2009;166(12):1347-54.

64. Klein AS, Skinner JB, Hawley KM. Adapted group-based dialectical behaviour therapy for binge eating in a practicing clinic: clinical outcomes and attrition. Eur Eat Disord Rev. 2012;20(3):e148-53.

65. Safer DL, Robinson AH, Jo B. Outcome from a randomized controlled trial of group therapy for binge eating disorder: comparing dialectical behaviour therapy adapted for binge eating to an active comparison group therapy. Behav Ther. 2010:41(1):106-20.

66. Masson PC, von Ranson KM, Wallace LM, Safer DL. A randomized wait-list controlled pilot study of dialectical behaviour therapy guided self-help for binge eating disorder. Behav Res Ther. 2013;51(11):723-8. doi:10.1016/j. brat.2013.08.001.

67. Hilbert A, Bishop ME, Stein Rl, Tanofsky-Kraff M, Swenson AK, Welch RR, et al. Long-term efficacy of psychological treatments for binge eating disorder. Br J Psychiatry. 2012;200(3):232-7.

68. McElroy SL, Guerdjikova Al, Mori N, O'Melia AM. Pharmacological management of binge eating disorder: current and emerging treatment options. Ther Clin Risk Manag. 2012;8:219-41. doi:10.2147/ TCRM.S25574.

69. Blom TJ, Mingione CJ, Guerdjikova Al, Keck Jr PE, Welge JA, McElroy SL. Placebo response in binge eating disorder: a pooled analysis of 10 clinical trials from one research group. Eur Eat Disord Rev. 2014;22(2):140-6. doi:10.1002/erv.2277. Epub 2014 Jan 8

70. Leombruni P, Pierò A, Lavagnino L, Brustolin A, Campisi S, Fassino S. A randomized, double-blind trial comparing sertraline and fluoxetine 6-month treatment in obese patients with Binge Eating Disorder. Prog Neuropsychopharmacol Biol Psychiatry. 2008;32(6):1599-605.

71. Calandra C, Russo RG, Luca M. Bupropion versus sertraline in the treatment of depressive patients with binge eating disorder: retrospective cohort study. Psychiatr Q. 2012;83(2):177-85.

72. Guerdjikova Al, McElroy SL, Winstanley EL, Nelson EB, Mori N, McCoy J, et al. Duloxetine in the treatment of binge eating disorder with depressive disorders: a placebo-controlled trial. Int J Eat Disord. 2012;45(2):281-9.

73. Leombruni P, Lavagnino L, Gastaldi F, Vasile A, Fassino S. Duloxetine in obese binge eater outpatients: preliminary results from a 12-week open trial. Hum Psychopharmacol. 2009;24(6):483-8.

74. Arbaizar B, Gomez-Acebo I, Llorca J. Efficacy of topiramate in bulimia nervosa and binge-eating disorder: a systematic review. Gen Hosp Psychiatry. 2008;30(5):471-5.

75. Marazziti D, Corsi M, Baroni S, Consoli G, Catena-Dell'Osso M. Latest advancements in the pharmacological treatment of binge eating disorder. Eur Rev Med Pharmacol Sci. 2012;16(15):2102-7.

76. Guerdjikova Al, McElroy SL, Welge JA, Nelson E, Keck PE, Hudson JI. Lamotrigine in the treatment of binge-eating disorder with obesity: a randomized, placebo-controlled monotherapy trial. Int Clin Psychopharmacol. 2009:24(3):150-8.

77. McElroy SL, Guerdjikova Al, Winstanley EL, O'Melia AM, Mori N, McCoy J, et al. Acamprosate in the treatment of binge eating disorder: a placebocontrolled trial. Int J Eat Disord. 2011:44(1):81-90.

78. McElroy SL, Guerdjikova Al, Winstanley EL, O'Melia AM, Mori N, Keck PE, et al. Sodium oxybate in the treatment of binge eating disorder: an open-label, prospective study. Int J Eat Disord. 2011;44(3):262-8. doi:10.1002/eat.20798.

79. Expert panel report. Guidelines for the management of overweight and obesity in adults. Obesity. 2013;22(S2):1973-739X. http://dx.doi.org/ 10.1002/oby.20660.

80. American Psychiatric Association. Practice Guideline for the treatment of patients with Eating Disorders. Am J Psychiatry. 2006;163:7.

81. Faulconbridge LF, Wadden TA, Thomas JG, Jones-Corneille LR, Sarwer DB, Fabricatore AN. Changes in depression and quality of life in obese 
individuals with binge eating disorder: bariatric surgery versus lifestyle modification. Surg Obes Relat Dis. 2013;9(5):790-6. doi:10.1016/j. soard.2012.10.010.

82. Wadden TA, Faulconbridge LF, Jones-Corneille LR, Sarwer DB, Fabricatore AN, Thomas JG, et al. Binge eating disorder and the outcome of bariatric surgery at one year: a prospective, observational study. Obesity. 2011;19(6):1220-8. doi:10.1038/oby.2010.336.

83. Beck NN, Mehlsen M, Støving RK. Psychological characteristics and associations with weight outcomes two years after gastric bypass surgery: Postoperative eating disorder symptoms are associated with weight loss outcomes. Eat Behav. 2012;13(4):394-7. doi:10.1016/j.eatbeh.2012.06.001.

84. Ashton $K$, Heinberg L, Windover A, Merrell J. Positive response to binge eating intervention enhances postoperative weight loss. Surg Obes Relat Dis. 2011;7(3):315-20. doi:10.1016/j.soard.2010.12.005.

85. Devlin MJ, Goldfein JA, Petkova E, Jiang H, Raizman PS, Wolk S, et al.

Cognitive behavioral therapy and fluoxetine as adjuncts to group behavioral therapy for binge eating disorder. Obes Res. 2005;13:1077-88,

\section{Submit your next manuscript to BioMed Central and take full advantage of:}

- Convenient online submission

- Thorough peer review

- No space constraints or color figure charges

- Immediate publication on acceptance

- Inclusion in PubMed, CAS, Scopus and Google Scholar

- Research which is freely available for redistribution 